\title{
Removal Mechanism Investigation of Ultraviolet Induced Nanoparticle Colloid Jet Machining
}

\author{
Xiaozong Song ${ }^{1, *}$ and Gui Gao ${ }^{2}$ \\ 1 School of Mechanical and Electronical Engineering, Lanzhou University of Technology, \\ Lanzhou 730050, China \\ 2 State Key Laboratory of Solid Lubrication, Lanzhou Institute of Chemical Physics, \\ Chinese Academy of Sciences, Lanzhou 730000, China; gaogui@licp.cas.cn \\ * Correspondence: songxz@lut.edu.cn; Tel.: +86-0931-2973860
}

check for

updates

Citation: Song, X.; Gao, G. Removal Mechanism Investigation of Ultraviolet Induced Nanoparticle Colloid Jet Machining. Molecules 2021, 26, 68. https://dx.doi.org/ $10.3390 /$ molecules 26010068

Received: 17 November 2020 Accepted: 22 December 2020 Published: 25 December 2020

Publisher's Note: MDPI stays neutral with regard to jurisdictional claims in published maps and institutional affiliations.

Copyright: () 2020 by the authors. Licensee MDPI, Basel, Switzerland. This article is an open access article distributed under the terms and conditions of the Creative Commons Attribution (CC BY) license (https: / / creativecommons.org/ licenses/by/4.0/).

\begin{abstract}
Ultraviolet induced nanoparticle colloid jet machining is a new ultra-precision machining technology utilizing the reaction between nanoparticles and the surface of the workpiece to achieve sub-nanometer ultra-smooth surface manufacturing without damage. First-principles calculations based on the density functional theory (DFT) were carried out to study the atomic material removal mechanism of nanoparticle colloid jet machining and a series of impacting and polishing experiments were conducted to verify the mechanism. New chemical bonds of Ti-O-Si were generated through the chemical adsorption between the surface adsorbed hydroxyl groups of the $\mathrm{TiO}_{2}$ cluster and the Si surface with the adsorption energy of at least $-4.360 \mathrm{eV}$. The two Si-Si back bonds were broken preferentially and the $\mathrm{Si}$ atom was removed in the separation process of $\mathrm{TiO}_{2}$ cluster from the $\mathrm{Si}$ surface realizing the atomic material removal. A layer of adsorbed $\mathrm{TiO}_{2}$ nanoparticles was detected on the Si surface after 3 min of fixed-point injection of an ultraviolet induced nanoparticle colloid jet. X-ray photoelectron spectroscopy results indicated that Ti-O-Si bonds were formed between $\mathrm{TiO}_{2}$ nanoparticles and $\mathrm{Si}$ surface corresponding to the calculation result. An ultra-smooth $\mathrm{Si}$ workpiece with a roughness of Rq $0.791 \mathrm{~nm}$ was obtained by ultraviolet induced nanoparticle colloid jet machining.
\end{abstract}

Keywords: first-principles simulation; nanoparticles; adsorption; ultra-smooth surface

\section{Introduction}

At present, ultra-smooth surfaces with high precision surface figure accuracy and extremely low surface roughness have been widely used in optics, electronic science and other fields, and have urgent needs in various fields [1-3]. In order to manufacture the ultra-smooth surface without damage, a variety of surface processing technologies and methods have been developed [4-6]. Chemical mechanical polishing is a kind of machining method to remove workpiece surface material by chemical mechanical interaction. However, it is mainly used for planarization of flat workpieces [7-10]. High energy beam processing technology uses high density energy beams (ion beam, electron beam, laser beam, etc.) to remove the surface material of a workpiece with a relatively high processing cost [11]. Magnetorheological polishing technology can achieve high-precision controllable polishing [12,13], the surface roughness after processing is about Ra $1 \mathrm{~nm}$. Fluid jet polishing utilizes the erosion effect of abrasive particles in a high-speed jet to remove the workpiece surface material, which can greatly improve the surface roughness and surface morphology [14], but defects such as tiny cracks may be introduced onto the workpiece surface. Laser assisted water jet micromachining uses the photo thermal effect of a highenergy laser beam to heat and soften the surface of hard and brittle materials, and then an abrasive water jet beam is used to slightly remove the softened area $[15,16]$. In the elastic emission machining, micro and nano abrasives in polishing fluid react with the workpiece surface under the action of a hydrodynamic pressure field in the micron scale gap between 
the polishing tool and the workpiece surface to remove the nano scale materials on the workpiece surface and can obtain super smooth surface. Elastic emission machining technology has high requirements for processing environment and machine tool stability [17]. Ultraviolet induced nanoparticle colloid jet machining is a new polishing technology which utilizes the interaction between nanoparticles in colloid and workpiece surfaces under the irradiation of catalytic light to remove the workpiece surface material at the atomic level and obtain an ultra-smooth surface, as is shown in Figure 1. The mechanism of surface interaction between nanoparticles and the workpiece surface in ultraviolet induced nanoparticle colloid jet machining has not been fully presented so far. How the hydroxyl groups in colloid act as active binding sites and form the connection between nanoparticles and the workpiece surface needs to be further studied. The quantification, investigation and knowledge of the behavior of nanoparticles in the colloid under ultraviolet radiation can help to properly understand the material removal mechanism in ultraviolet induced nanoparticle colloid jet machining.

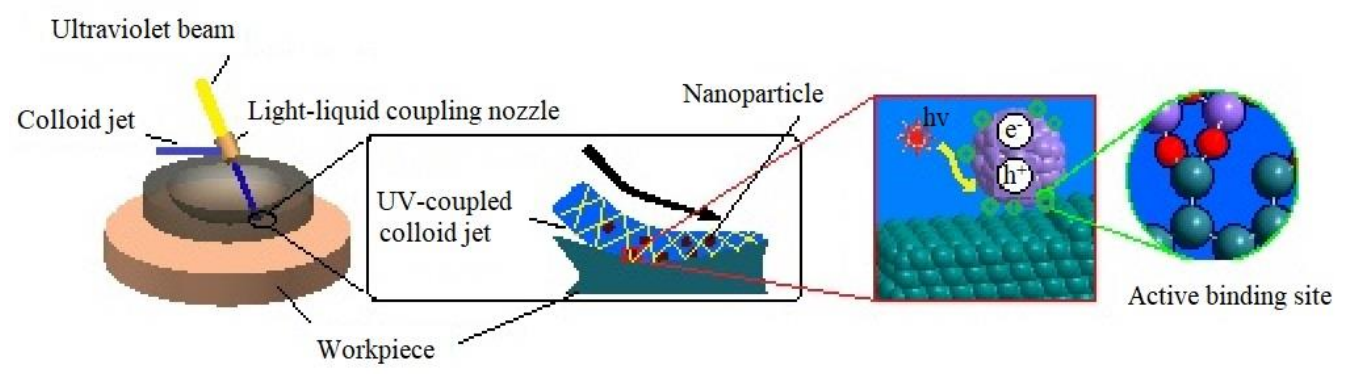

Figure 1. Schematic diagram of ultraviolet induced nanoparticle colloid jet machining.

\section{Calculation Method and Model}

All density functional theory (DFT) calculations in this study were performed by using the CASTEP (Cambridge Sequential Total Energy Package) program [18,19] with Vanderbilttype ultrasoft pseudo potentials [20] and a plane-wave expansion of the wave functions. The Perdew-Burke-Ernzerhof (PBE) exchange correlation functional under generalized gradient approximation (GGA) was used as the exchange-associative interaction, and the ultrasoft pseudopotential (USPP) [21] was used to describe the interaction between electrons and ions. The cut-off energy was set as $500 \mathrm{eV}$ for the $\mathrm{TiO}_{2}$ cluster and $300 \mathrm{eV}$ for the Si surface system, respectively. The sample of the Brillouin zone K point was $3 \times 3 \times 1$. The geometries of the system were relaxed until the residual forces were less than $0.05 \mathrm{eV} / \AA$, the stress was less than $0.1 \mathrm{GPa}$, the total energy was less than $2.0 \times 10^{-5} \mathrm{eV} /$ atom and the change in displacement was less than $0.002 \AA$. Spin polarization was not considered in the calculation.

In the process of ultraviolet induced nanoparticle colloid jet machining, anatase titanium dioxide colloid was compounded as the polishing agent. $\mathrm{A} \mathrm{TiO}_{2}$ cluster model $\left(\mathrm{Ti}_{8} \mathrm{O}_{14} \mathrm{H}_{26}\right)$ and silicon supercell were set up to analyze the adsorption mechanism of $\mathrm{TiO}_{2}$ nanoparticles on the silicon workpiece surface in ultraviolet induced nanoparticle colloid jet machining, as is shown in Figure 2.

The calculated band gap of the $\mathrm{TiO}_{2}$ unit cell was $2.282 \mathrm{eV}$, which was smaller than the experimental value of $3.2 \mathrm{eV}$. However, since the band gap calculated by the GGA method is always less than the actual value, it is feasible to use the calculated data for comparison. The lattice constants of the anatase titanium dioxide model were $\mathrm{a}=\mathrm{b}=3.776 \AA, \mathrm{c}=9.486$ $\AA$. The structure of anatase titanium dioxide was optimized, and the optimized Ti-O bond lengths were $1.930 \AA$ and $1.973 \AA$, which were very similar to the experimental data $1.934 \AA$ and $1.980 \AA$. The dangling bonds of the $\mathrm{TiO}_{2}$ cluster were saturated with $\mathrm{H}$. The calculated band gap of the Si unit cell was $1.099 \mathrm{eV}$, which was smaller than the experimental data (about $1.2 \mathrm{eV}$ ). Considering the actual profile of the workpiece surface, an irregular convex $\mathrm{Si}$ (100) surface with periodic boundary conditions was set up as shown in Figure 2e,f. The Si surface was cut out from a Si $4 \times 4 \times 3$ supercell. The lattice parameters of the silicon 
supercell were as follows: $\mathrm{a}=\mathrm{b}=23.04 \AA \mathrm{c}=44.93 \AA$, and the vacuum layer thickness was $30.0 \AA$. All the above models were optimized before calculation.

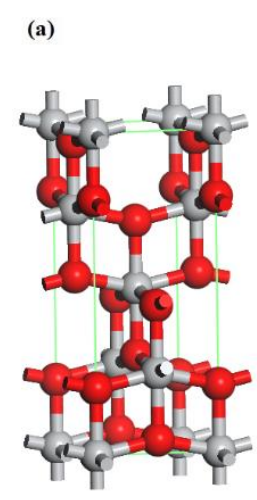

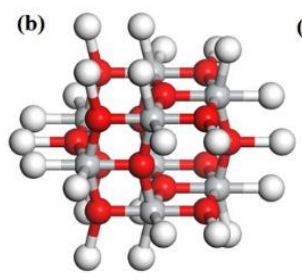

(d)

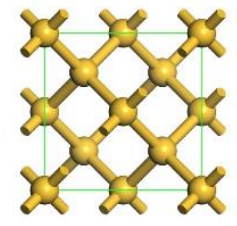

(c)

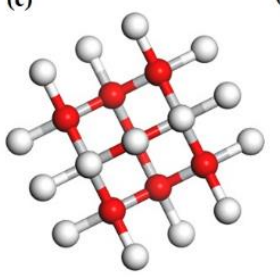

(e)

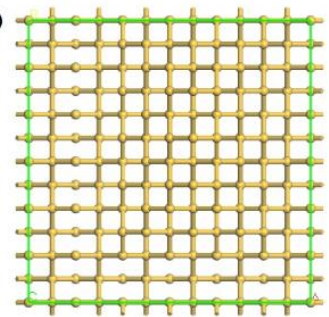

(f)

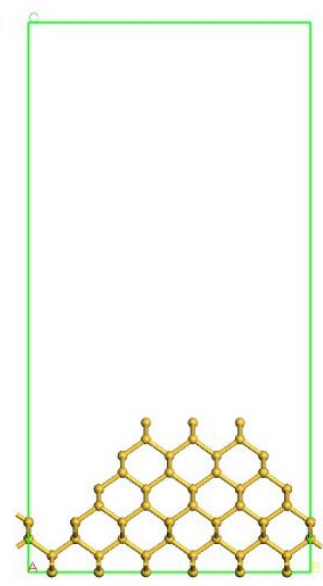

Figure 2. Calculated structures of anatase $\mathrm{TiO}_{2}$ cluster model and monocrystalline silicon surface. (a) $\mathrm{Unit}_{\text {cell }}$ of $\mathrm{TiO} \mathrm{O}_{2}$ (b) Top view, and (c) side view of $\mathrm{TiO}_{2}$ cluster where white, red and grey are hydrogen, oxygen and titanium atoms, respectively; (d) Unit cell of $\mathrm{Si}$; (e) Top view, and (f) side view of Si (100) surface.

\section{Calculation Results and Discussion}

\subsection{Adsorption of Hydroxyl Group on the Surface of Titanium Dioxide Cluster and} Monocrystalline Silicon

A large number of hydroxyl $(\mathrm{OH})$ groups can be produced in the $\mathrm{TiO}_{2}$ colloid under the action of photocatalysis of ultraviolet light [22]. These $\mathrm{OH}$ groups can interact with the unsaturated atoms on the surface of the nanoparticles and the workpiece to achieve surface adsorption and generate surface hydroxyl groups. Figure 3 shows the adsorption process of $\mathrm{OH}$ group on a suspended unsaturated $\mathrm{Ti}$ atom of $\mathrm{TiO}_{2}$ cluster. Figure $3 \mathrm{~b}$ shows the relationship between the total system energy and the distance in the adsorption process. According to the intensity of the curve variation, it is considered that the interaction between $\mathrm{OH}$ group and $\mathrm{TiO}_{2}$ cluster changes from a weak interaction to a strong interaction when the distance is about $3.0 \AA$, and the interaction becomes repulsive when the distance is about $1.8 \AA$. Therefore, it can be considered that the $\mathrm{OH}$ is adsorbed onto the $\mathrm{TiO}_{2}$ cluster and bonded at this point. In the colloid, the process of $\mathrm{OH}$ group adsorbing on the $\mathrm{TiO}_{2}$ nanoparticle is an exothermic process with the adsorption energy of about $1.87 \mathrm{eV}$. After bonding, the structure of the system was optimized, and the final structure of the adsorption system was obtained, as shown in Figure 3c. The $\mathrm{OH}$ group in the colloid finally adsorbs on the target $\mathrm{Ti}$ atom with $\mathrm{O}$ atom end inward, and becomes the surface adsorbed hydroxyl group with Ti-O bond $1.794 \AA$.

The density of states (DOS) is important in further understanding the reaction process. Figure 4a shows the total DOS of $\mathrm{TiO}_{2}$ unit cell, $\mathrm{TiO}_{2}$ cluster $\left(\mathrm{Ti}_{8} \mathrm{O}_{14} \mathrm{H}_{25}\right)$ and final state (FS) $\left(\mathrm{Ti}_{8} \mathrm{O}_{15} \mathrm{H}_{26}\right)$. It can be seen from the figure that, compared with the total DOS of the $\mathrm{TiO}_{2}$ unit cell, the DOS of the $\mathrm{FS}\left(\mathrm{Ti}_{8} \mathrm{O}_{15} \mathrm{H}_{26}\right)$ moves downward, that is, the conduction band position is more negative, while the conduction band and valence band position of $\mathrm{TiO}_{2}$ cluster $\left(\mathrm{Ti}_{8} \mathrm{O}_{14} \mathrm{H}_{25}\right)$ move more and more significantly. It is considered that the $\mathrm{TiO}_{2}$ cluster $\left(\mathrm{Ti}_{8} \mathrm{O}_{14} \mathrm{H}_{25}\right)$ contains two oxygen vacancies, and the $\mathrm{FS}\left(\mathrm{Ti}_{8} \mathrm{O}_{15} \mathrm{H}_{26}\right)$ contains one oxygen vacancy. The oxygen vacancy impurity anatase is equivalent to the doped semiconductor. The higher the concentration of oxygen vacancies, the more electrons enter the conduction band, and the more negative shifts of conduction and valence band positions are [23]. It can be seen from Figure 4, that the Ti 4s orbit shifts to the right after the OH group adsorbing on the surface of $\mathrm{TiO}_{2}$ cluster, the energy level increases and the electronic activity increases. The electron strength of the Ti $3 p$ orbit decreases. The Ti $3 \mathrm{~d}$ orbit shifts to the right and the 
electron strength decreases. The $\mathrm{O} 2 \mathrm{~s}, \mathrm{O} 2 \mathrm{p}$ and $\mathrm{H} 1$ s orbits shift to the left, and the energy level decrease. In the $-7 \sim 0 \mathrm{eV}$ section, hybridization occurs between the $\mathrm{O} 2 \mathrm{p}$ and the $\mathrm{Ti}$ $3 \mathrm{~d}$ orbits. In the above process, the electrons are redistributed, the $\mathrm{O} 2 \mathrm{p}$ and $\mathrm{Ti} 3 \mathrm{~d}$ orbits obtain electrons, and the Ti $4 \mathrm{~S}$ and the Ti $3 p$ orbits lose electrons, and a chemical bond is formed between $\mathrm{Ti}$ and $\mathrm{O}$ atoms.

(a)

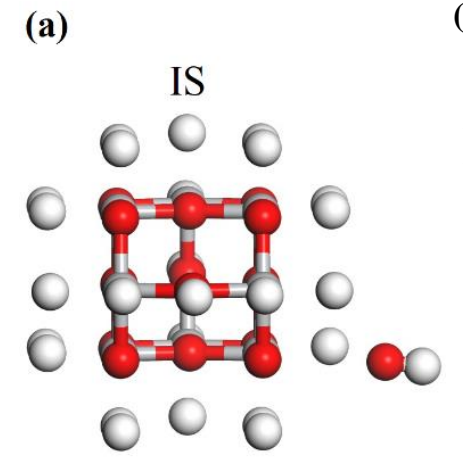

(b)

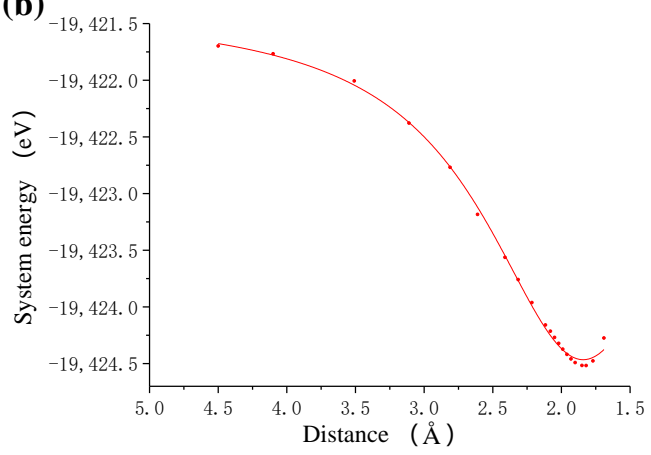

(c)

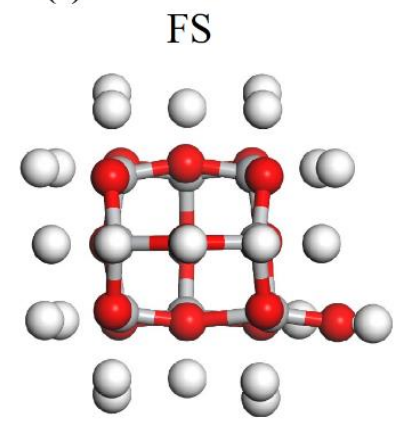

Figure 3. The process of $\mathrm{OH}$ group adsorbing on $\mathrm{TiO}_{2}$ cluster. (a) Initial state (IS); (b) system energy; (c) final state (FS) where white, red and grey balls are hydrogen, oxygen and titanium atoms, respectively.

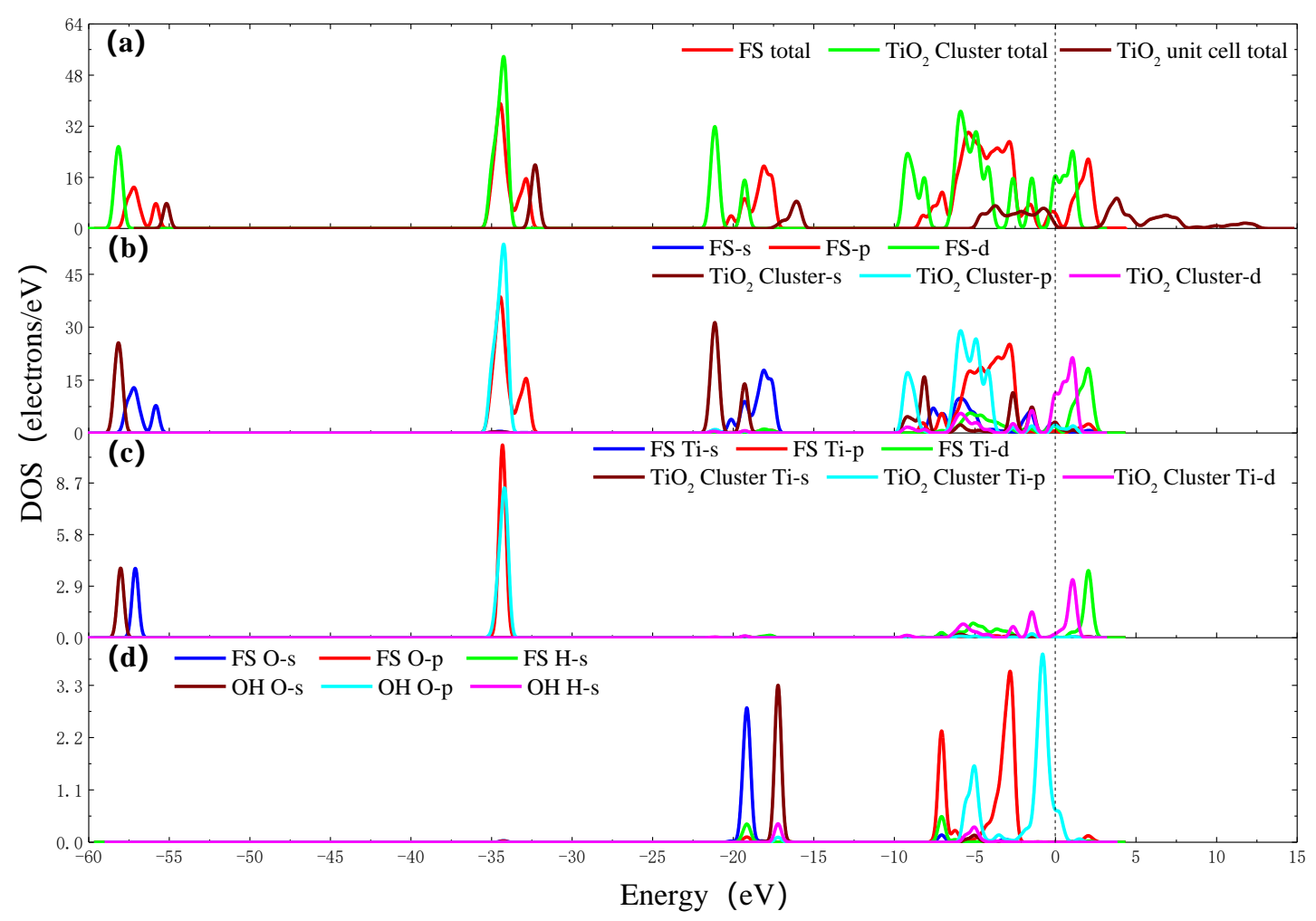

Figure 4. The density of states (DOS) of $\mathrm{OH}$ group adsorbing on the surface of $\mathrm{TiO}_{2}$ cluster. (a) Total DOS of FS, $\mathrm{TiO}_{2}$ cluster and $\mathrm{TiO}_{2}$ unit cell; (b) Partial density of states (PDOS) of FS and $\mathrm{TiO}_{2}$ cluster; (c) PDOS of adsorption site Ti atoms of FS and $\mathrm{TiO}_{2}$ cluster; (d) PDOS of $\mathrm{O}$ atom and $\mathrm{H}$ atom of $\mathrm{FS}$ and $\mathrm{OH}$ group.

According to the calculation model, many unsaturated dangling bonds exist on the $\mathrm{Si}$ surface, so there are many possible bonding sites for the $\mathrm{OH}$ group. In the process of ultraviolet induced nanoparticle colloid jet machining, the location of impacting nanoparticles on the $\mathrm{Si}$ surface is random in principle. However, considering the influence of the actual workpiece surface morphology, the impacting nanoparticles will interact with the atoms at the highest position of Si surface firstly. Therefore, in the calculation of this paper, we 
chose a Si atom with the highest position on the $\mathrm{Si}$ surface as the target $\mathrm{Si}$ atom to study. Similar to the above process, the adsorption process of the $\mathrm{OH}$ group on the Si surface is shown in Figure 5. In this process, the $\mathrm{O}$ atom of the $\mathrm{OH}$ group is always close to the fixed direction of the target $\mathrm{Si}$ atom. According to the relationship curve of Figure $5 b$, the interaction between the $\mathrm{OH}$ group and the $\mathrm{Si}$ surface changes from a weak interaction to a strong interaction when the distance is about $2.6 \AA$, and the interaction becomes repulsive when the distance is about $1.65 \AA$. Again, it is considered that the $\mathrm{OH}$ is adsorbed on the $\mathrm{Si}$ surface and bonded with the target $\mathrm{Si}$ atom at this point. Because there is a large number of dangling bonds without passivation on the Si surface, it is easy enough for the $\mathrm{OH}$ group to adsorb on the $\mathrm{Si}$ surface and the adsorption energy is about $4.47 \mathrm{eV}$. Figure $5 \mathrm{c}$ shows the optimized final structure of the system after bonding. The $\mathrm{OH}$ group becomes a surface adsorbed hydroxyl group with Si-O bond $1.656 \AA$.

(a)

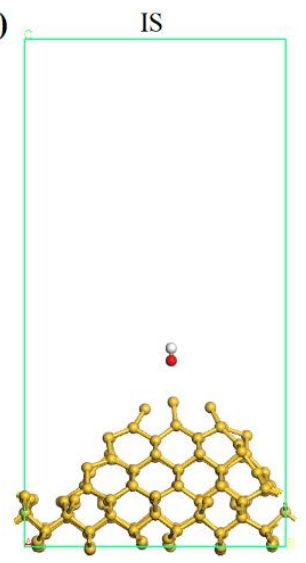

(b)

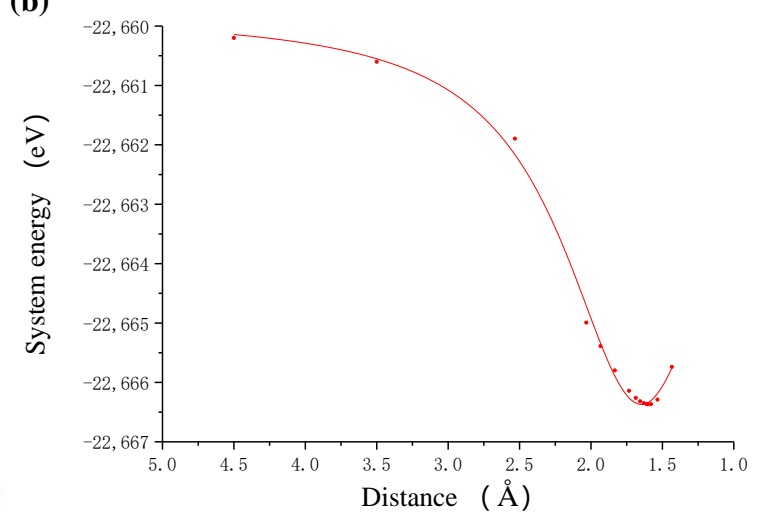

(c)

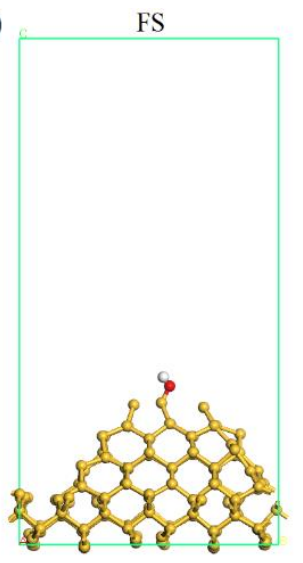

Figure 5. The process of $\mathrm{OH}$ group adsorbing on Si surface. (a) Initial state; (b) system energy; (c) final state where white and balls are hydrogen and oxygen atoms, respectively.

Figure 6 shows the density of states of the $\mathrm{OH}$ group adsorbing on the Si surface. Figure $6 \mathrm{a}, \mathrm{b}$ shows the total DOS of the Si unit cell, Si $4 \times 4 \times 1$ supercell, the Si surface total and the FS total. The valence band of the total DOS of the Si $4 \times 4 \times 1$ supercell is similar to that of the $\mathrm{Si}$ unit cell, but the conduction band is greatly reduced. The Si surface, which is cut out from a Si $4 \times 4 \times 3$ supercell, has a similar valence band peak with $\mathrm{Si}$ $4 \times 4 \times 1$ supercell, while the conduction band is further reduced compared with Si 4 $\times 4 \times 1$ supercell. The valence band and conduction band of the Si surface move down simultaneously, and the Fermi surface of the Si surface enter the conduction band. It is considered that the Si surface has a large surface area and a large number of dangling bonds without passivation, there are more electrons in the higher energy quantum states, the surface states of the dangling bonds seriously affect the distribution of the DOS of the $\mathrm{Si}$ surface. The results of the PDOS show that the Si 3s orbit shifts to the left and the electron strength decreases. The $\mathrm{Si} 3 \mathrm{p}$ orbit shifts to the left and the electron strength increases. The $\mathrm{O} 2 \mathrm{~s}, \mathrm{H} 1 \mathrm{~s}$, orbits shift to the left from $-17.25 \mathrm{eV}$ and hybridizes with $\mathrm{Si} 3 \mathrm{~s}$ and $\mathrm{Si} 3 \mathrm{p}$ orbits at $-21.17 \mathrm{eV}$. In the $-10 \sim 0 \mathrm{eV}$ section, hybridization occurs between the $\mathrm{O} 2 \mathrm{p}, \mathrm{Si} 3 \mathrm{p}$ and $\mathrm{Si}$ 3 s orbits. The electrons are redistributed after $\mathrm{OH}$ group adsorbing on the $\mathrm{Si}$ surface. The $\mathrm{O} 2 \mathrm{p}, \mathrm{O} 2 \mathrm{~s}$ and $\mathrm{Si} 3 \mathrm{p}$ orbits get electrons, the $\mathrm{Si} 3 \mathrm{~s}$ orbit lose electrons, and a chemical bond is formed between $\mathrm{Si}$ and $\mathrm{O}$ atoms. 


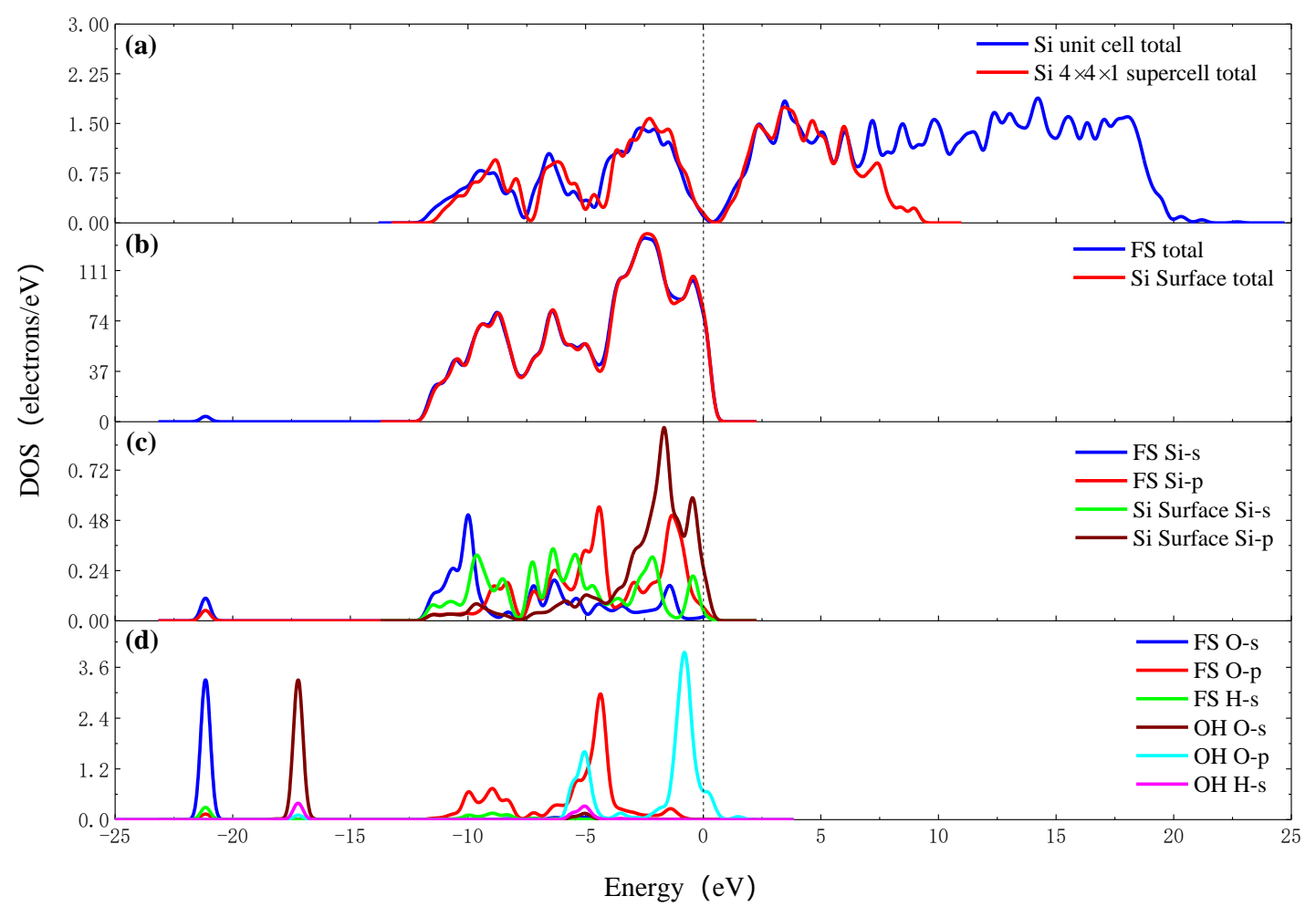

Figure 6. The DOS of $\mathrm{OH}$ group adsorbing on the Si surface. (a) Total DOS of Si unit cell and $4 \times 4 \times 1$ supercell; (b) total DOS of FS and Si surface; (c) PDOS of adsorption site Si atoms of FS and Si surface; (d) PDOS of O atom and H atom of FS and $\mathrm{OH}$ group.

\subsection{Adsorption of Titanium Dioxide Cluster on the Silicon Surface}

In ultraviolet induced nanoparticle colloid jet machining, the interaction between the impacting nanoparticles and the workpiece surface are of important influence for the removal of workpiece materials. Utilizing the above calculation results, the interaction process between the $\mathrm{TiO}_{2}$ cluster and the hydroxyl silicon workpiece surface was calculated. Figure 7 shows the process of incident impacting $\mathrm{TiO}_{2}$ cluster approaching to silicon surface. According to the relationship between the system energy and the approaching distance shown in Figure $7 \mathrm{~b}$, when the $\mathrm{TiO}_{2}$ cluster is approaching the $\mathrm{Si}$ surface, a repulsive interaction exists permanently between the $\mathrm{TiO}_{2}$ cluster and the $\mathrm{Si}$ surface. The system energy significantly increases when the adsorption distance ranges from $2.0 \AA$ to $1.3 \AA$. The main reason is that the two oxygen atoms of the $\mathrm{OH}$ groups adsorbed on $\mathrm{TiO}_{2}$ cluster and Si surface are infinitely close to each other, and the nuclear-nuclear repulsion between the nuclei of the two oxygen atoms makes the system energy significantly increased. Between the adsorption distance of $2.0 \AA$ and $1.3 \AA$, the $\mathrm{OH}$ group on $\mathrm{TiO}_{2}$ cluster will impact with $\mathrm{OH}$ group on $\mathrm{Si}$ surface, and two atomic nuclei collide with each other. When the atomic orbits of two atoms overlapping, a covalent bond may be formed to reduce the energy of the system. 
(a)

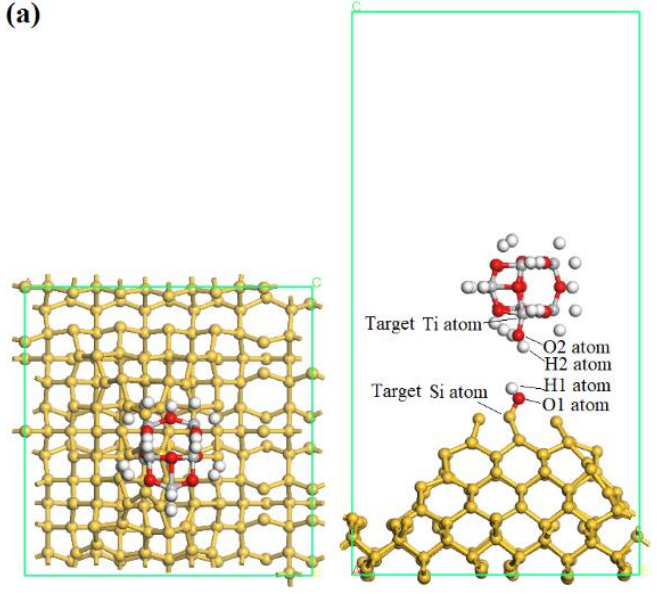

(b)

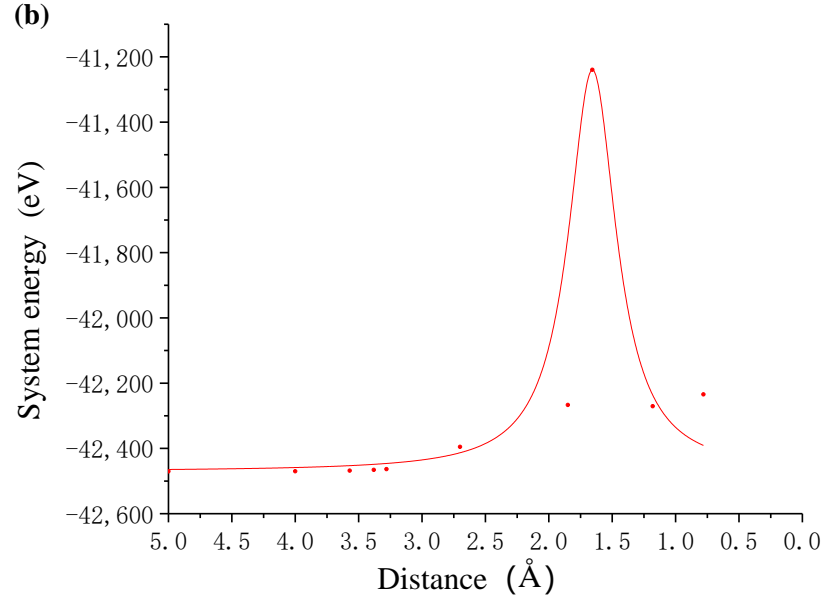

Figure 7. The incident impacting $\mathrm{TiO}_{2}$ cluster approaching to silicon surface. (a) Schematic diagram of incident state where white, red, grey and yellow balls are hydrogen, oxygen, titanium and silicon atoms, respectively; (b) system energy with the distance between $\mathrm{TiO}_{2}$ cluster and silicon surface.

Figure 8a shows the interaction between the incident $\mathrm{TiO}_{2}$ cluster and the silicon surface in the ultraviolet induced nanoparticle colloid jet machining, in which new chemical bonds (Ti-O-Si bonds) and products (a chemically adsorbed water molecule $\mathrm{H}_{2} \mathrm{O}$ ) are generated. The supposed process can be depicted as follow:

$$
\mathrm{A}-\mathrm{OH}+\mathrm{OH}-\mathrm{B} \rightarrow \mathrm{A}-\mathrm{O}-\mathrm{B}+\mathrm{H}_{2} \mathrm{O}(\mathrm{Ch}),
$$

where A represents $\mathrm{TiO}_{2}$ cluster and $\mathrm{B}$ represents $\mathrm{Si}$ atoms on the workpiece surface, $\mathrm{H}_{2} \mathrm{O}$ $(\mathrm{CH})$ is a chemically adsorbed water molecule.

(a)

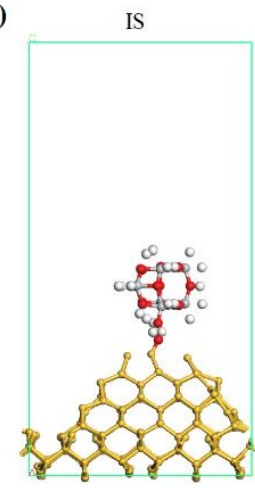

TS

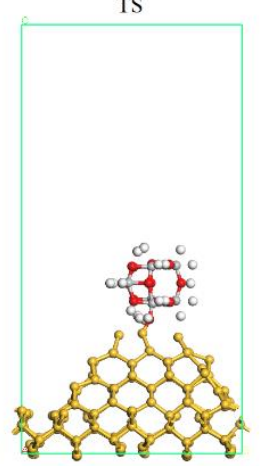

FS

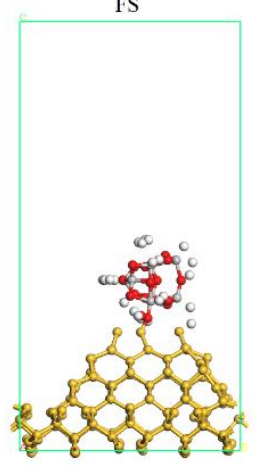

(b)

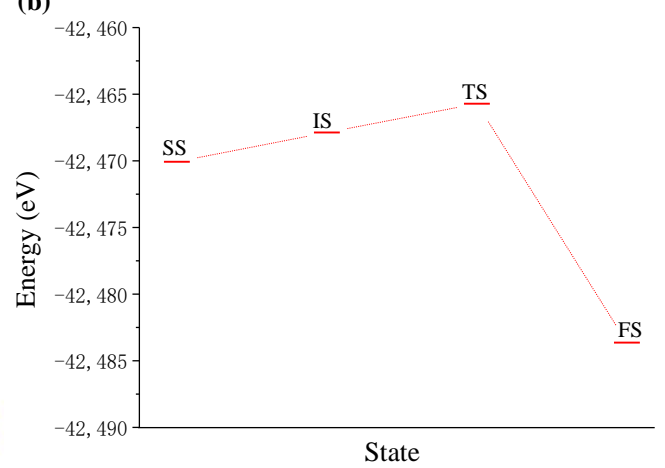

Figure 8. The interaction between incident $\mathrm{TiO}_{2}$ cluster and silicon surface. (a) Interaction states where white, red, grey and yellow balls are hydrogen, oxygen, titanium and silicon atoms, respectively; (b) system energy of interaction states.

According to the results of Figure 8b, taking the energy of the separated state (SS) as the reference value, the adsorption energies of initial state (IS) and FS are $-2.199 \mathrm{eV}$ and $13.568 \mathrm{eV}$, respectively. The adsorption energy of the saddle point (TS) on the potential energy surface between the two states is $-4.360 \mathrm{eV}$. From the IS state, the activation energy of the reaction is $-2.161 \mathrm{eV}$, which is an endothermic reaction. In the process of ultraviolet induced nanoparticle colloid jet machining the kinetic energy of high speed incident nanoparticles can provide energy for the endothermic reaction to make the reaction proceed smoothly.

Figure 9 shows the density of states of $\mathrm{TiO}_{2}$ cluster adsorbing on the $\mathrm{Si}$ surface. The DOS of interaction between $\mathrm{TiO}_{2}$ cluster and the $\mathrm{Si}$ surface were analyzed. The results show that the $\mathrm{Si} 3 \mathrm{~s}$ and $3 \mathrm{p}$ orbits of the target $\mathrm{Si}$ atom shift to the right and the electron 
strength increases. The Ti $4 \mathrm{~s}, 3 \mathrm{p}$ and $3 \mathrm{~d}$ orbits of the target Ti atom shift to the left. The O $2 \mathrm{~s}$ and $\mathrm{O} 2 \mathrm{p}$ orbits of the $\mathrm{O} 2$ atom shift to the left, the electron strength of the $\mathrm{O} 2 \mathrm{~s}$ increases and the $\mathrm{O} 2 \mathrm{p}$ decreases. The $\mathrm{O} 2 \mathrm{p}$ orbit of the $\mathrm{O} 1$ atom shifts to the left and the electron strength increases. The $\mathrm{O} 2 \mathrm{~s}$ and $\mathrm{O} 2 \mathrm{p}$ orbits of the $\mathrm{O} 2$ atom hybridize with the $\mathrm{Si} 3 \mathrm{~s}, \mathrm{Si} 3 \mathrm{p}$, Ti $3 p$ and Ti 4 s orbits and form Ti-O-Si chemical bonds. The $\mathrm{O} 2 \mathrm{~s}$ and $\mathrm{O} 2 \mathrm{p}$ orbits of the O1 atom hybridize with the $\mathrm{H} 1$ s orbits of $\mathrm{H} 1$ and the $\mathrm{H} 2$ atoms and form a $\mathrm{H}_{2} \mathrm{O}$ molecule. In the above process, the $\mathrm{Si} 2 \mathrm{p}, \mathrm{Ti} 4 \mathrm{~s}, \mathrm{Ti} 3 \mathrm{p}$ and $\mathrm{O} 2 \mathrm{p}(\mathrm{O} 2$ atom) orbits gain electrons, the $\mathrm{Si} 3 \mathrm{~s}$ and $\mathrm{O} 2 \mathrm{p}$ (O1 atom) orbits lose electrons.

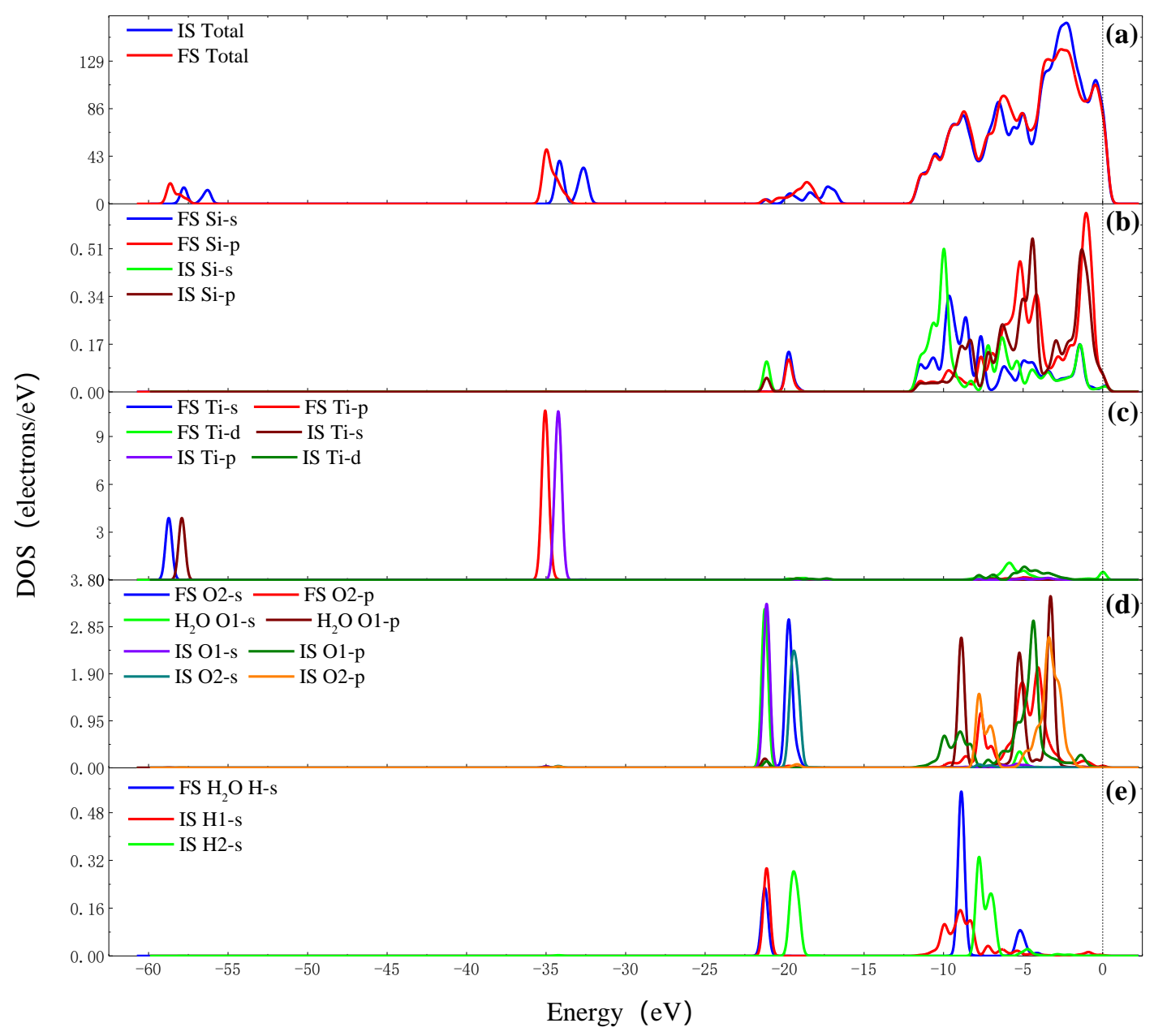

Figure 9. The DOS of $\mathrm{TiO}_{2}$ cluster adsorbing on the Si surface. (a) Total DOS of FS and IS; (b) PDOS of target Si atoms of FS and IS; (c) PDOS of target Ti atoms of FS and IS; (d) PDOS of O1 and $\mathrm{O} 2$ atoms of FS and $\mathrm{H}_{2} \mathrm{O}$ molecule and IS; (e) PDOS of $\mathrm{H} 1$ and $\mathrm{H} 2$ atoms of $\mathrm{FS}$ and $\mathrm{H}_{2} \mathrm{O}$ molecule and IS.

\subsection{Separation of Titanium Dioxide Cluster from the Surface of Monocrystalline Silicon}

In ultraviolet induced nanoparticle colloid jet machining, the shear viscosity of the high-speed flowing colloid results in the nanoparticles adsorbed on the workpiece surface being separated from the surface. There are three kinds of chemical bonds between $\mathrm{TiO}_{2}$ cluster and the $\mathrm{Si}$ surface, two $\mathrm{Si}-\mathrm{Si}$ bonds, one $\mathrm{Si}-\mathrm{O}$ bond and one O-Ti bond, as is shown in Figure 10a. Among them, when the Si-O bond and the O-Ti bond are broken, the $\mathrm{TiO}_{2}$ cluster will be separated from the $\mathrm{Si}$ surface without any material removal from the $\mathrm{Si}$ surface. Only when the two Si-Si bonds are broken will the target $\mathrm{Si}$ atom on the silicon workpiece surface be removed. 
(a)

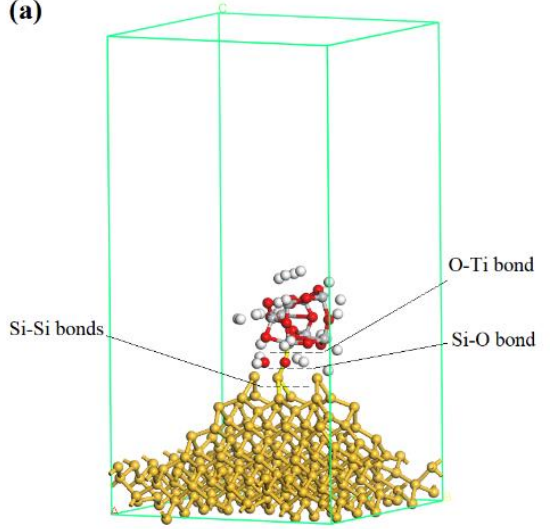

(b)

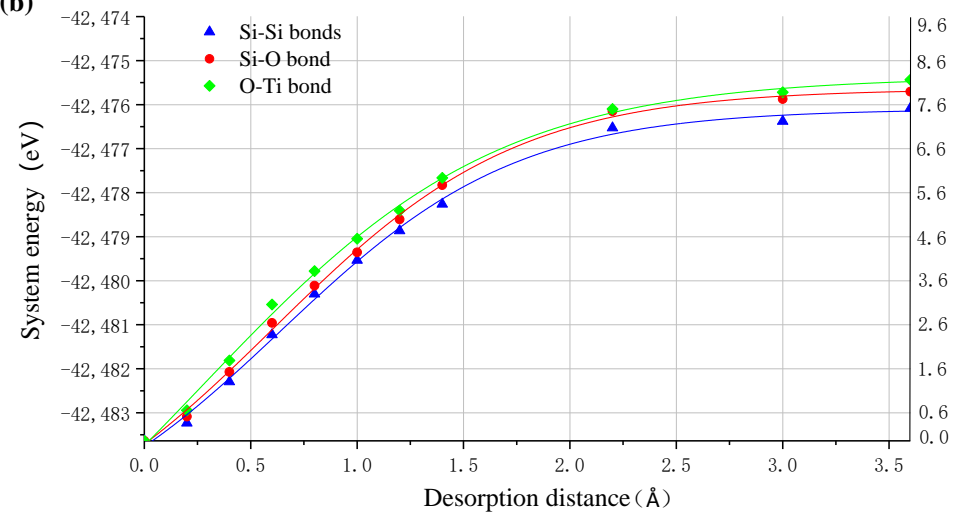

Figure 10. (a) Three kinds of bonds between $\mathrm{TiO}_{2}$ cluster and the Si surface where white, red, grey and yellow balls are hydrogen, oxygen, titanium and silicon atoms, respectively; (b) energy curve of $\mathrm{TiO}_{2}$ cluster separating from $\mathrm{Si}$ surface.

Figure 10b shows the relationship between the system energy and the bond length of the above three kinds of chemical bonds when the chemically adsorbed $\mathrm{TiO}_{2}$ cluster is separated from the Si surface. According to the results, when the separating distance is about $1.4 \AA$, the energy curves of the system become smooth. It can be considered that at this point, each target bond begins to be broken and the $\mathrm{TiO}_{2}$ cluster is separated from the $\mathrm{Si}$ surface. The calculation results showed that the order of energy needed to break the above three bonds is that: $E_{\mathrm{Ti}-\mathrm{O} \text { bond }}>E_{\mathrm{O}-\mathrm{Si} \text { bond }}>E_{2 \mathrm{Si}-\mathrm{Si} \text { bonds }}$. In the process of the $\mathrm{TiO}_{2}$ cluster being separated from the silicon surface, the two Si-Si back bonds will be broken preferentially in the separation process. When the two Si-Si back bonds are broken, the target $\mathrm{Si}$ atom of the silicon surface is removed together with the $\mathrm{TiO}_{2}$ cluster, thus realizing the atomic level removal of the workpiece material.

Figure 11 shows the density of states of $\mathrm{TiO}_{2}$ cluster separating from the $\mathrm{Si}$ surface. Compared with the total DOS curve before bond breaking, because of the increase in the free bonds on the Si surface after the bond breaking of two Si-Si bonds-one Si-O bond and one O-Ti bond-there are more peaks in the total DOS curves when the $\mathrm{TiO}_{2}$ cluster is separating from Si surface with a distance of $1.4 \AA$. The Si 3 s and 3p orbits of adsorption site $\mathrm{Si}$ atoms shift to the left, accompanying the electron strength increase after the two $\mathrm{Si}-\mathrm{Si}$ bonds breaking and the electrons transferred from the Si 3p orbit to the Si 3s orbit. After the Si-O bond breaking, the Si 3 s and $3 p$ orbits shift to the right as well as the electron strength decrease, and the $\mathrm{O} 2 \mathrm{~s}$ and $2 \mathrm{p}$ orbits shift to the right as well as the electron strength increase. The $\mathrm{Si} 3 \mathrm{~s}, 3 \mathrm{p}$ and $\mathrm{O} 2 \mathrm{~s}$ orbits gain electrons from the $\mathrm{O} 2 \mathrm{p}$ orbit in the process of the Si-O bond breaking. After the O-Ti bond breaking, the Ti 4s, 3p and 3d orbits shift to the left with the electron strength of Ti $3 p$ decrease, and the $\mathrm{O} 2 \mathrm{~s}$ and $2 p$ orbits shift to the right as well as the electron strength increase. The $\mathrm{O} 2 \mathrm{~s}$ and $\mathrm{O} 2 \mathrm{p}$ orbits gain electrons from the $\mathrm{Si} 3 \mathrm{~s}, 3 \mathrm{p}$ orbits, and the $\mathrm{Ti} 4 \mathrm{~s}, 3 \mathrm{p}$ and $3 \mathrm{~d}$ gain electrons from the $\mathrm{TiO}_{2}$ cluster.

The above calculation model and results reflect the main bonding effects of the interface reactions between $\mathrm{TiO}_{2}$ nanoparticles and the silicon workpiece to remove material at the atomic level in ultraviolet induced nanoparticle colloid jet machining. 


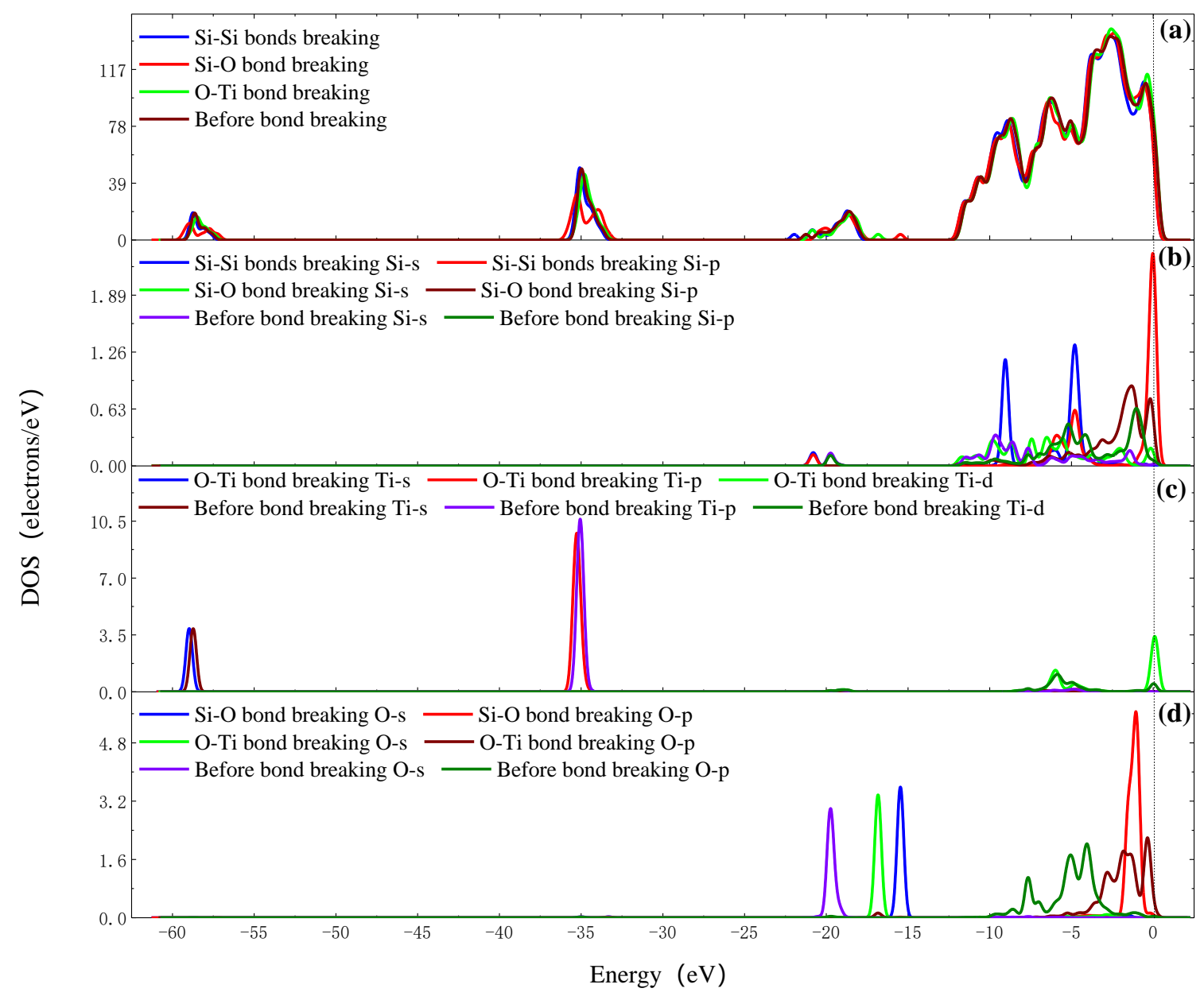

Figure 11. The DOS of $\mathrm{TiO}_{2}$ cluster separating from the Si surface. (a) Total DOS; (b) PDOS of adsorption site Si atoms; (c) PDOS of adsorption site Ti atoms; (d) PDOS of adsorption site $\mathrm{O}$ atoms.

\section{Results and Discussion}

The instantaneous adsorption process of nanoparticles on the workpiece surface had been observed in previous study [24]. In order to verify the above calculation results experimentally, the experiment of ultraviolet induced nanoparticle colloid jet machining was carried out using the self-developed equipment to detect the adsorption of $\mathrm{TiO}_{2}$ nanoparticles on the silicon surface.

After 3 min of fixed-point injection of an ultraviolet induced nanoparticle colloid jet, the silicon workpiece surface was removed from the polishing table, soaked in deionized water and dried naturally at room temperature. Then, the morphology, microanalysis and chemical composition of the silicon workpiece surface were characterized by means of Scanning electron microscope (SEM) and X-ray photoelectron spectroscopy (XPS).

Figure 12a shows the SEM morphology of the silicon surface on which the adsorbed $\mathrm{TiO}_{2}$ nanoparticles have been observed. The SEM results indicate that there are reunion adsorption phenomena of the $\mathrm{TiO}_{2}$ nanoparticles after the fixed-point injection of ultraviolet coupled nanoparticle colloid jet, which leads to the increases in particle size of the $\mathrm{TiO}_{2}$ nanoparticles adsorbing on the silicon surface. The reason for this phenomenon is that the polishing colloid used in the experiment has been reused many times to carry out relevant polishing experiments. Figure $12 b, c$ shows the areas and results of scanning electron microscope energy spectrum (SEM-EDS) microanalysis of the silicon surface, respectively. The results indicate that the chemical composition of the silicon workpiece surface after fixed-point injection of ultraviolet coupled nanoparticle colloid jet is mainly composed of $\mathrm{Si}$ elements, as well as a small amount of $\mathrm{Ti}, \mathrm{O}$ and $\mathrm{C}$ elements. 
(a)

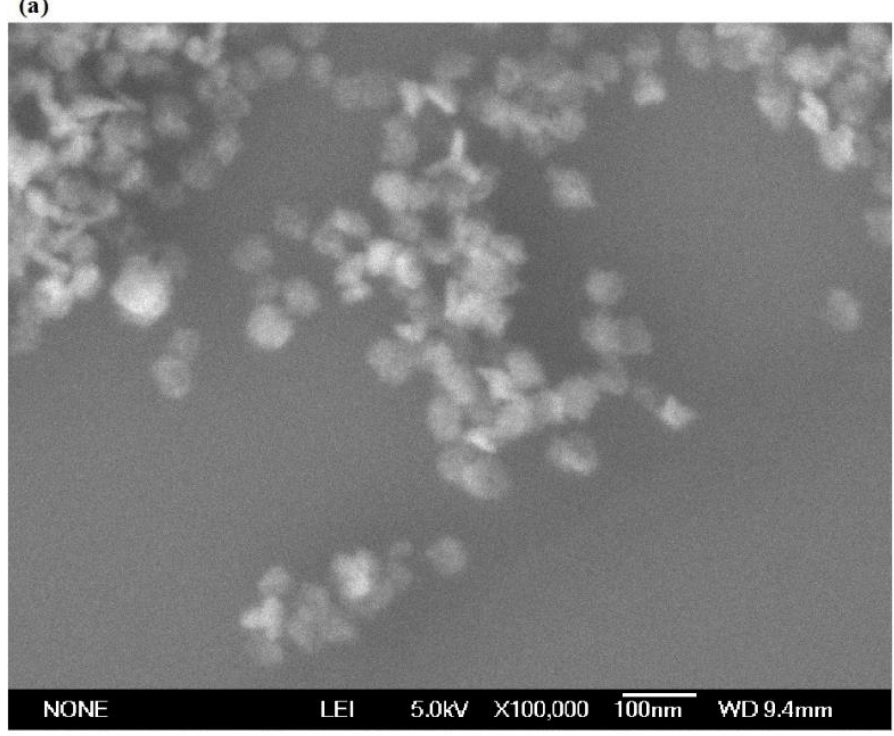

(b)
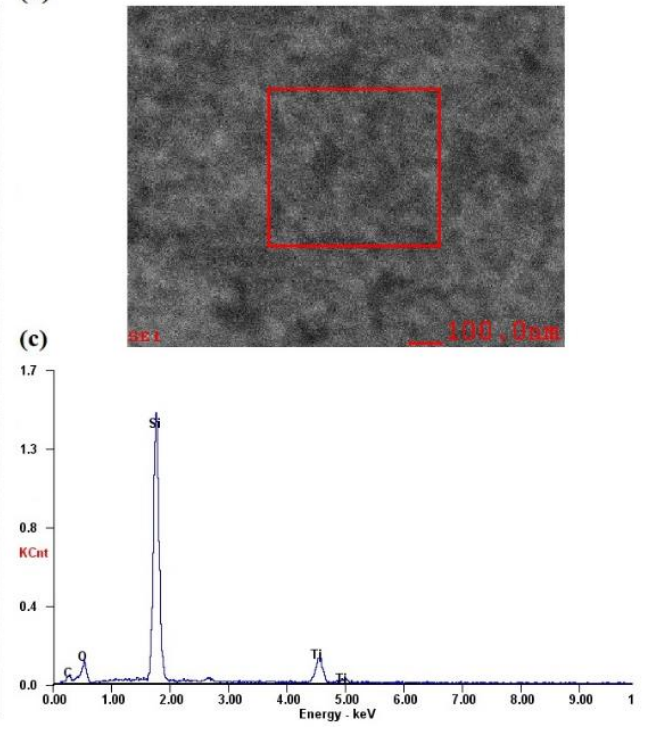

Figure 12. The morphology and microanalysis of $\mathrm{TiO}_{2}$ nanoparticles adsorbing on Si surface. (a) The morphology; (b) the microanalysis areas and (c) the microanalysis results.

X-ray photoelectron spectroscopy (XPS) was also used to analyze the silicon surface before and after $\mathrm{TiO}_{2}$ nanoparticle colloid jet impacting. Figure 13a,b shows the full spectrum of XPS of the original silicon surface and the silicon surface after $\mathrm{TiO}_{2}$ nanoparticle colloid jet impacting under ultraviolet irradiation, respectively.

(a)

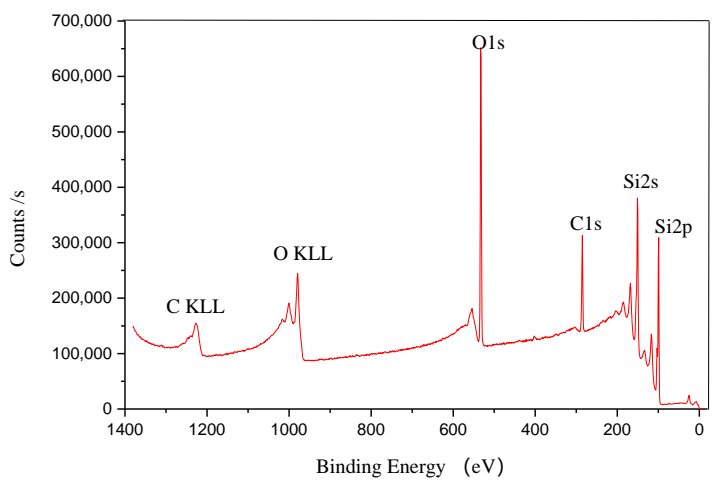

(b)

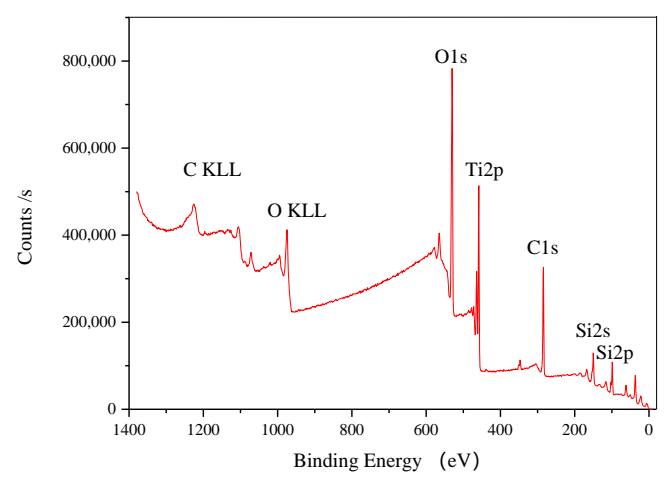

Figure 13. Full spectrum of (a) XPS of the original Si surface; (b) XPS of Si surface after $\mathrm{TiO}_{2}$ nanoparticle colloid jet impacting under ultraviolet irradiation.

Compared with the standard XPS spectrum, the elements on the original silicon surface are Si, C and O. Strong Si peak appears on the silicon surface, which is the main characteristic peak of the silicon surface. The existence of the $\mathrm{O}$ element is mainly due to the oxidation of silicon in contact with air. Since the detection depth of XPS is about $10 \mathrm{~nm}$, and the surface layer is oxidized, the peak of $\mathrm{O}$ element in the full spectrum is obvious. There may be two reasons for the existence of $C$, one is the residual in the pre-process, and the other is that the sample surface is polluted by the environment due to too long a storage time. Si, C, O and $\mathrm{Ti}$ are the main elements of the silicon surface after $\mathrm{TiO}_{2}$ nanoparticle colloid jet impacting under ultraviolet irradiation. The weak Si peak and strong Ti peak appear in the spectrum, which indicates that the chemical adsorption of incident $\mathrm{TiO}_{2}$ nanoparticles on the silicon surface occur in the fixed-point injection of the ultraviolet induced nanoparticle colloid jet. 
Figure 14 shows the fine XPS spectrum of the original silicon surface before and after $\mathrm{TiO}_{2}$ nanoparticle colloid jet impacting. As is shown in Figure 14a, the fine spectrum of $\mathrm{Si}$ $2 p$ is composed of two peaks, which are located near $99 \mathrm{eV}$ and $103 \mathrm{eV}$ [25]. The peak near $99 \mathrm{eV}$ is significantly higher than the peak near $103 \mathrm{eV}$. Compared with the standard XPS spectrum, the binding energy of $99 \mathrm{eV}$ is $\mathrm{Si}$ and $103 \mathrm{eV}$ is $\mathrm{SiO}_{2}$. Therefore, the $\mathrm{Si}$ elements on both of the surfaces mainly existed in the state of $\mathrm{Si}$ and $\mathrm{SiO}_{2}$, and those in the form of the $\mathrm{Si}$ element are obviously more abundant than those in the form of $\mathrm{SiO}_{2}$. Due to the adsorption of $\mathrm{TiO}_{2}$, the content of $\mathrm{Si}$ detected on the surface after nanoparticle colloid jet impacting is relatively lower. Among them, the peaks of $\mathrm{Si} 2 \mathrm{p}$ on the original silicon surface are at $98.78 \mathrm{eV}$ and $102.48 \mathrm{eV}$, and the peaks of silicon surface after nanoparticle colloid jet impacting are at $98.78 \mathrm{eV}$ and $102.68 \mathrm{eV}$, the shift of $0.2 \mathrm{eV}$ to a high energy indicates that there may be chemical changes in the presence of electron transfer. According to the Figure $14 \mathrm{~b}$, there are no $\mathrm{TiO}_{2}$ nanoparticles on the original silicon surface. The fine spectrum of $\mathrm{Ti} 2 \mathrm{p}$ on the $\mathrm{Si}$ workpiece surface after nanoparticle colloid jet impacting is split into two levels due to the spin orbit coupling of electrons. The peak near $464 \mathrm{eV}$ corresponds to Ti 2 p 1/2, and the peak near $459 \mathrm{eV}$ corresponds to Ti $2 \mathrm{p} 3 / 2$ [26,27]. The peak position of Ti 2 p $1 / 2$ and Ti 2 p $3 / 2$ is $464.18 \mathrm{eV}$ and $458.58 \mathrm{eV}$, respectively. The splitting value of standard $\mathrm{TiO}_{2}$ is $5.7 \mathrm{eV}$, while that of the $\mathrm{Si}$ workpiece surface after nanoparticle colloid jet impacting is $5.6 \mathrm{eV}$, which is $0.1 \mathrm{eV}$ less than that of the standard $\mathrm{TiO}_{2}$. In Figure 14c, the $\mathrm{O} 1 \mathrm{~s}$ peak on the original $\mathrm{Si}$ surface is $532.18 \mathrm{eV}$, which indicates that the presence of $\mathrm{O}$ element is mainly $\mathrm{SiO}_{2}$. The $\mathrm{O}$ 1s peak of $529.78 \mathrm{eV}$ on the $\mathrm{Si}$ workpiece surface after nanoparticle colloid jet impacting belongs to $\mathrm{TiO}_{2}$, while the $\mathrm{O} 1 \mathrm{~s}$ peak at $531.98 \mathrm{eV}$ belongs to $\mathrm{SiO}_{2}$. However, the binding energy of $\mathrm{O} 1 \mathrm{~s}$ on the $\mathrm{Si}$ workpiece surface shifts $0.2 \mathrm{eV}$ to a low energy, relative to the original Si surface. Combining these results with the results of the $\mathrm{Si} 2 \mathrm{p}$ shift of $0.2 \mathrm{eV}$ to a high energy, the $\mathrm{O} 1 \mathrm{~s}$ shift of $0.2 \mathrm{eV}$ to a low energy and the splitting value of $\mathrm{TiO}_{2}$ is $0.1 \mathrm{eV}$ lower than the standard value. These results together indicate that new chemical bonds of Ti-O-Si are formed between $\mathrm{TiO}_{2}$ nanoparticles and the Si surface in the process of nanoparticle colloid jet impacting [28,29]. According to the results presented in Figure $14 \mathrm{~d}$, the C element exists on the surface of $\mathrm{Si}$ workpiece before polishing, which may be the residual in the pre-process. In the process of ultraviolet induced nanoparticle colloid jet impacting, new $\mathrm{C}$ elements are introduced to the $\mathrm{Si}$ workpiece surface by dispersant and surfactant in the colloid polishing solution.

(a)

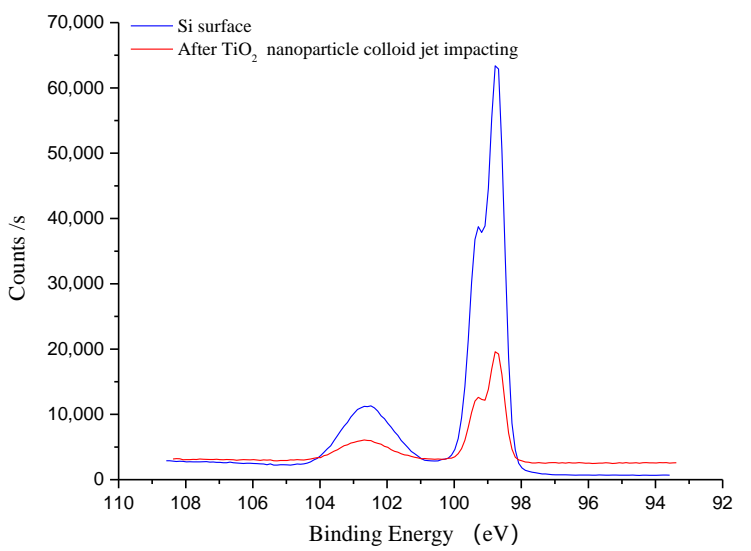

(b)

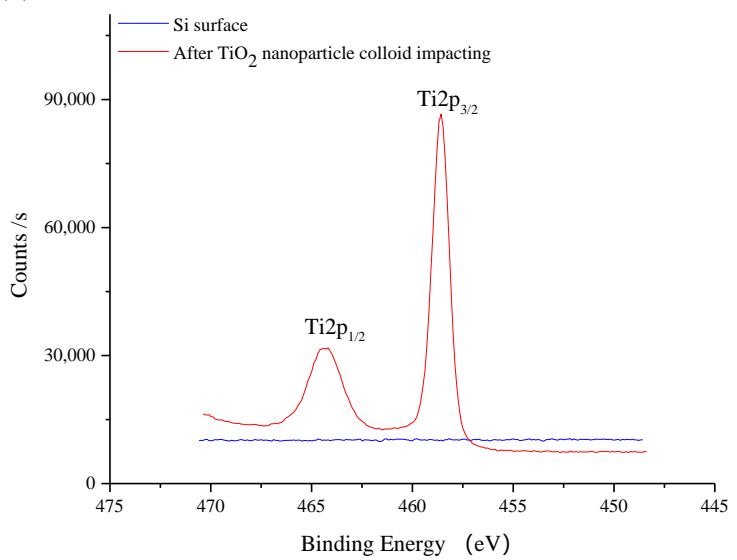

Figure 14. Cont. 
(c)

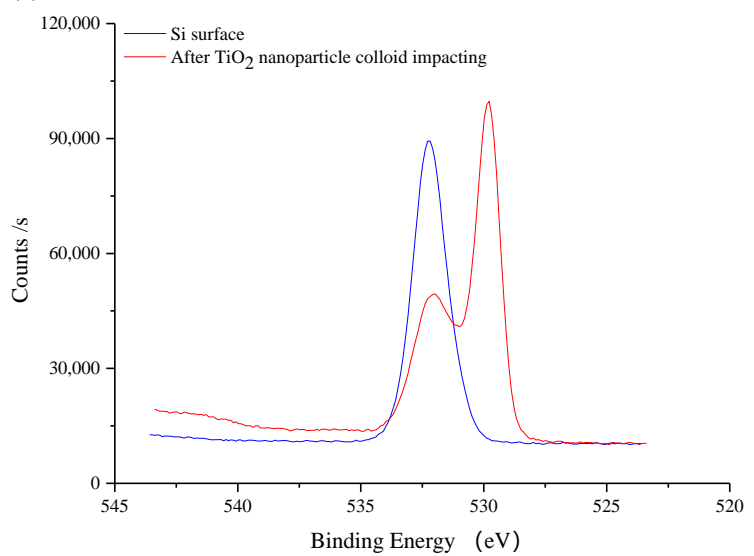

(d)

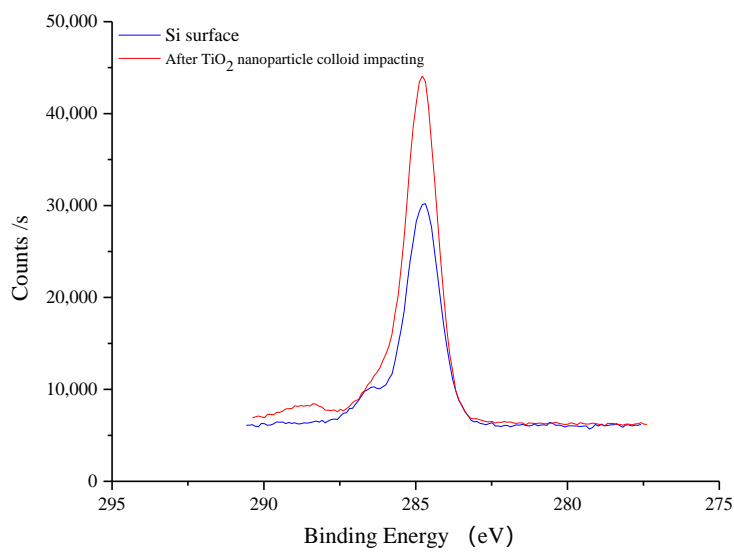

Figure 14. The fine spectrum of XPS on the silicon surface before and after $\mathrm{TiO}_{2}$ nanoparticle colloid jet impacting. (a) Si $2 \mathrm{p}$ scans; (b) Ti 2p scans; (c) O 1s scans; (d) C 1s scans.

The ultra smooth surface polishing experiment of the silicon workpiece was carried out on the ultraviolet induced nanoparticle colloid jet machining system with a polishing time of $120 \mathrm{~min}$. The silicon workpiece surface was cleaned with deionized water under a pressure of $1 \mathrm{MPa}$ to completely remove the remaining nanoparticles on the surface. Atomic force microscope (AFM, Brook, Dimension icon) was used to characterize the surface morphology and roughness of the workpiece before and after ultraviolet induced nanoparticle colloid jet machining with a measurement area of $10 \mu \mathrm{m} \times 10 \mu \mathrm{m}$.

Figure 15 shows the AFM surface morphology and roughness results of Si surface before ultraviolet induced nanoparticle colloid jet machining. In the analysis area of about $86 \mu \mathrm{m}^{2}$ the surface roughness is $\mathrm{Rq} 1.70 \mathrm{~nm}(\mathrm{Ra} 0.965 \mathrm{~nm})$. Combining with the AFM micrograph, a large number of surface protrusions, concave valleys and scratches left by the pre-process can be found on the original Si workpiece surface, and the maximum $\mathrm{p}-\mathrm{v}$ value of surface protrusions and surface concave valleys is $55.4 \mathrm{~nm}$. The AFM surface morphology and roughness results of the Si surface after ultraviolet induced nanoparticle colloid jet machining are shown in Figure 16. Within the same analysis area, the surface roughness is decreased to $\mathrm{Rq} 0.791 \mathrm{~nm}(\mathrm{Ra} 0.629 \mathrm{~nm})$. The surface protrusions, concave valleys and scratches are obviously removed and the maximum $p-v$ value of the surface protrusions and surface concave valleys is reduced to $8.91 \mathrm{~nm}$.

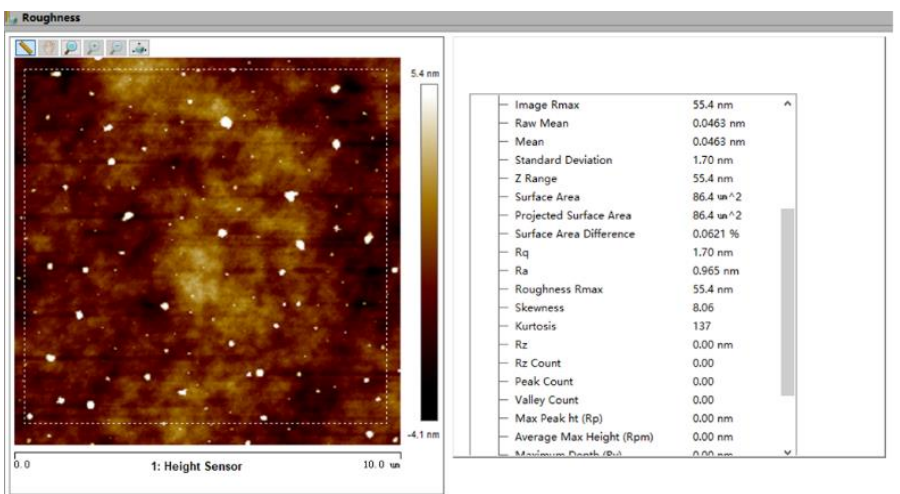

(a)

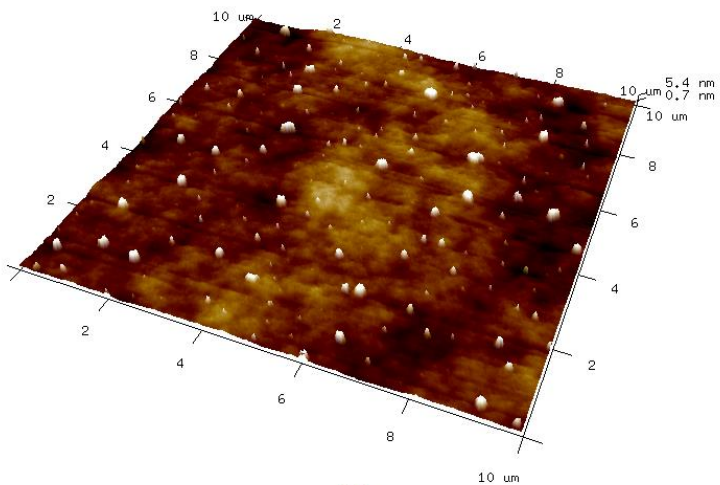

(b)

Figure 15. The original Si workpiece surface. (a) Surface roughness and (b) surface morphology. 


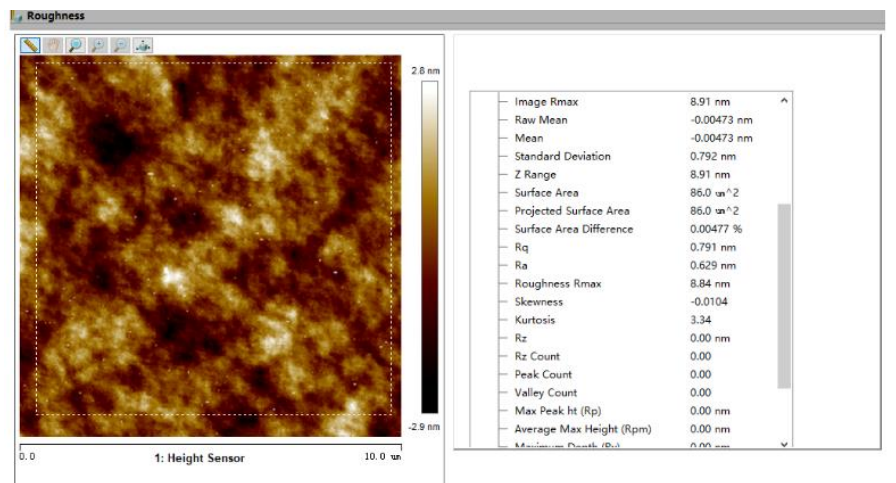

(a)

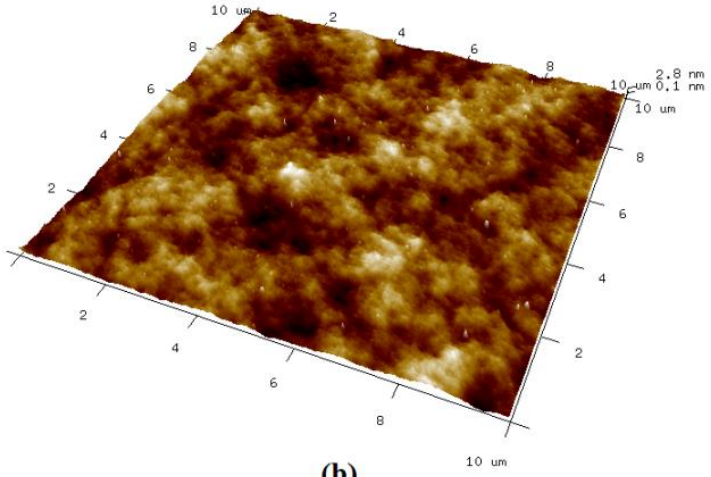

(b)

Figure 16. The Si workpiece surface after ultraviolet induced nanoparticle colloid jet machining. (a) Surface roughness and (b) surface morphology.

The above experimental results could support and verify the calculation results. Firstly, The SEM morphology and SEM-EDS results show that the adsorbed $\mathrm{TiO}_{2}$ nanoparticles had been observed on the Si workpiece surface after the fixed-point injection of an ultraviolet induced nanoparticle colloid jet, which was consistent with the calculated results of the $\mathrm{TiO}_{2}$ clusters adsorbing on the Si surface. Secondly, the results of the XPS analysis showed that new chemical bonds of Ti-O-Si were formed between the $\mathrm{TiO}_{2}$ nanoparticles and the Si surface in the process of nanoparticle colloid jet impacting, which further verified the possible reaction mechanism proposed in the calculation. Finally, in the ultra smooth surface polishing experiment the jet pressure was $1 \mathrm{MPa}$ and the incident velocity of the nanoparticles was less than $30 \mathrm{~m} / \mathrm{s}$. At the impacting velocity, the incident energy of the $20 \mathrm{~nm}$ nanoparticle was too small to cause material deformation and material removal on the workpiece surface. Therefore, it could be considered that in ultraviolet induced nanoparticle colloid jet machining the surface material of the Si workpiece was removed by the chemical process shown in the previous calculation.

\section{Materials and Methods}

The nozzle used in the experiments was a cosine type light liquid coupling nozzle. The injection pressure was $1 \mathrm{MPa}$, and the distance between nozzle and Si workpiece surface was $4 \mathrm{~mm}$. Figure 17 shows the system diagram of ultraviolet induced nanoparticle colloid jet machining.

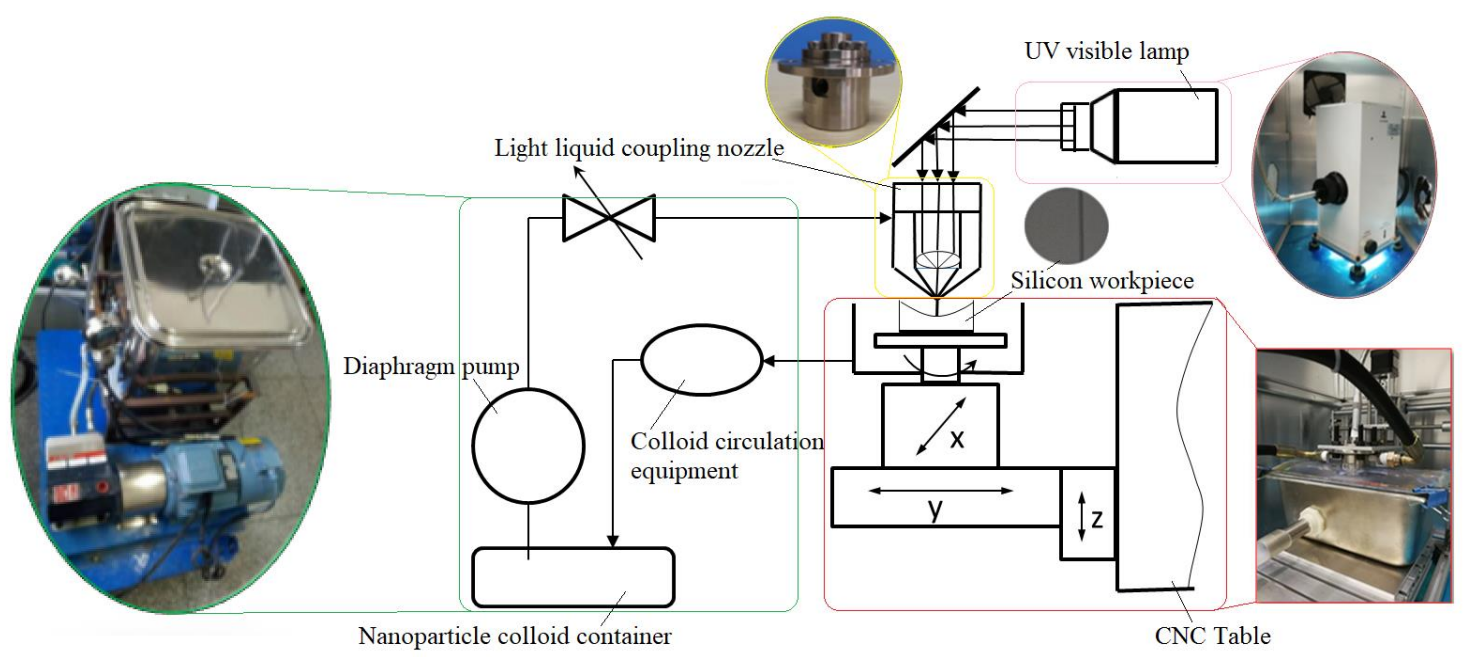

Figure 17. The system diagram of ultraviolet induced nanoparticle colloid jet machining. 
In the experiment, the nanoparticles in the polishing colloid were anatase $\mathrm{TiO}_{2}$ with the volume concentration of $10 \%$ and $\mathrm{pH}$ value of 7 . Figure 18a shows the SEM micrograph of $\mathrm{TiO}_{2}$ nanoparticles which was carried out on SU8020 high resolution field emission scanning electron microscope of HITACHI (Hitachi High-Technologies Corporation, Tokyo, Japan). Phase analysis of $\mathrm{TiO}_{2}$ nanoparticles was carried out on the D8 advance X-ray powder diffractometer (XRD, the $\mathrm{X}$-ray source is $\mathrm{K} \alpha$ ray of $\mathrm{Cu}$ Target with wavelength of $0.15405 \mathrm{~nm}$, the scanning speed is $12^{\circ} / \mathrm{min}$, the scanning range is $20^{\circ} \sim 80^{\circ}$ and the sampling interval is $0.02^{\circ}$, Bruker, Karlsruhe, Germany). Figure $18 \mathrm{~b}$ shows the $\mathrm{XRD}$ pattern of $\mathrm{TiO}_{2}$ nanoparticles. Figure 18c shows the particle size distribution of the $\mathrm{TiO}_{2}$ nanoparticles measured by nanoparticle size analyzer (The Zetasizer Nano ZS particle size potentiometer of Malvern company, Malvern, UK, with a scanning speed of 1000/s). The diameter of the $\mathrm{TiO}_{2}$ nanoparticles were mainly distributed in the range of $20 \sim 30 \mathrm{~nm}$. Ultravioletvisible light was provided by a $500 \mathrm{~W}$ high pressure mercury lamp with the intensity of $145 \mathrm{~mW} / \mathrm{cm}^{2}$ measured by an optical power meter.

(a)

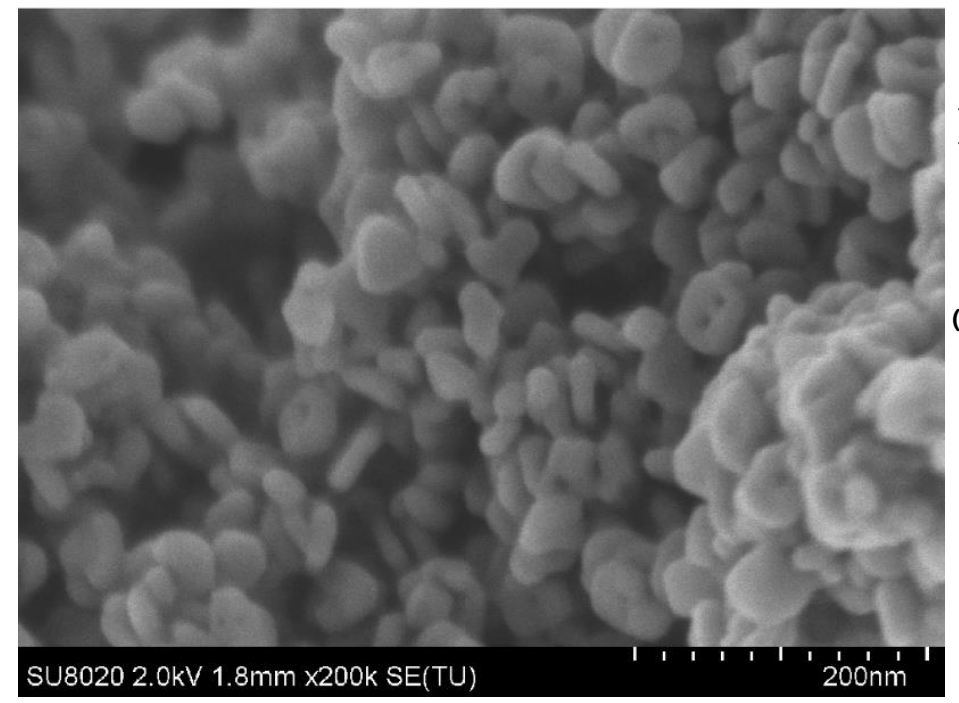

(b)

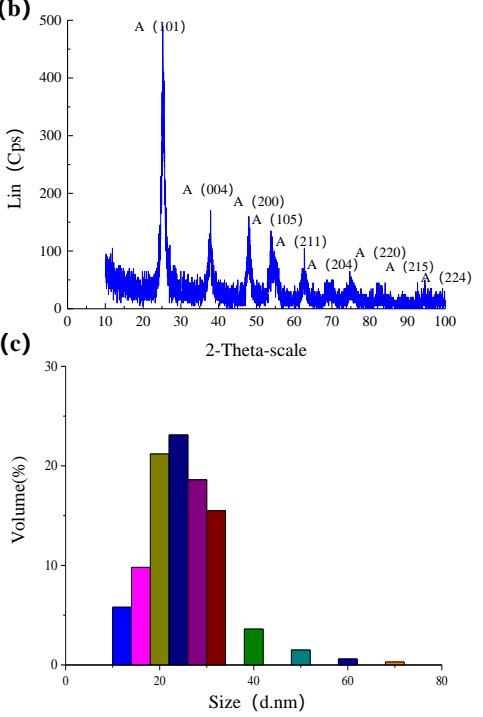

Figure 18. $\mathrm{TiO}_{2}$ nanoparticles used in the experiments. (a) SEM, (b) XRD pattern and (c) Diameter distribution.

\section{Conclusions}

In this work, the atomic structure and electronic structure of the $\mathrm{TiO}_{2}$ cluster and the Si surface in the impacting process were studied based on the first principle calculations, to investigate the material removal mechanism of ultraviolet induced nanoparticle colloid jet machining. In the colloid, the $\mathrm{OH}$ groups easily adsorbed on the unpaired dangling bonds of the $\mathrm{TiO}_{2}$ cluster and the $\mathrm{Si}$ surface and formed stable surface adsorbed hydroxyl groups through exothermic processes. In the impacting process of the $\mathrm{TiO}_{2}$ cluster onto the Si surface, new chemical bonds of Ti-O-Si were generated through the chemical adsorption between the surface adsorbed hydroxyl groups of the $\mathrm{TiO}_{2}$ cluster and Si surface. At least $4.360 \mathrm{eV}$ of energy was required to make the endothermic process proceed forward. Calculation results showed that the two Si-Si back bonds were the weakest bond among the three chemical bonds between the $\mathrm{TiO}_{2}$ cluster and the Si surface and were broken preferentially in the separation process of the $\mathrm{TiO}_{2}$ cluster from the silicon surface. The target $\mathrm{Si}$ atom was removed together with the $\mathrm{TiO}_{2}$ cluster and the atomic material removal of the workpiece surface was realized in ultraviolet induced nanoparticle colloid jet machining. A layer of adsorbed $\mathrm{TiO}_{2}$ nanoparticles was detected on the Si surface after $3 \mathrm{~min}$ of fixed-point injection of an ultraviolet coupled nanoparticle colloid jet by the scanning electron microscope. According to the X-ray photoelectron spectroscopy analysis results, the existing form of $\mathrm{Si}, \mathrm{O}$ and $\mathrm{Ti}$ elements changed in chemical form after nanoparticle colloid jet impacting, which indicated that new chemical bonds of Ti-O-Si were formed. 
An ultra-smooth Si workpiece with surface roughness of Rq $0.791 \mathrm{~nm}(\mathrm{Ra} 0.629 \mathrm{~nm})$ was obtained and a large number of surface bulges and scratches were removed from the $\mathrm{Si}$ workpiece surface after $120 \mathrm{~min}$ of ultraviolet induced nanoparticle colloid jet machining.

Author Contributions: X.S. carried out the literature retrieval, chart making, research design, experimental research, data analysis and manuscript writing; G.G. carried out software calculations, data analyses and paper revision. All authors have read and agreed to the published version of the manuscript.

Funding: This research was funded by National Natural Science Foundation of China (No. 51565031).

Data Availability Statement: The data presented in the article are available from the corresponding author.

Conflicts of Interest: The authors declare there is no conflict of interest.

Sample Availability: Samples of the colloid and workpieces are available from the corresponding author.

\section{References}

1. Mori, Y.; Yamamura, K.; Endo, K.; Yamauchi, K.; Yasutake, K.; Goto, H.; Kakiuchi, H.; Sano, Y.; Mimura, H. Creation of perfect surfaces. J. Cryst. Growth. 2005, 275, 39-50. [CrossRef]

2. Duan, F.L.; Wang, J.X.; Luo, J.B. Phase transformations of monocrystalline silicon surface under nanoparticle collision. Acta. Physica. Sinica. 2007, 56, 6552-6557. [CrossRef]

3. Xu, J.; Luo, J.B.; Lu, X.C.; Wang, L.L.; Pan, G.S.; Wen, S.Z. Atomic scale deformation in the solid surface induced by nanoparticle impacts. Nanotechnology 2005, 16, 859-864. [CrossRef]

4. Hao, P.; Lei, H.; Chen, R. Cerium-incorporated SBA-15-type materials for CMP: Synthesis, characterisation, and CMP application on hard disk substrate. Int. J. Abras. Technol. 2011, 4, 255-265. [CrossRef]

5. Zhang, F.; Song, X.; Zhang, Y.; Luan, D. Figuring of an ultra-smooth surface in nanoparticle colloid jet machining. J. Micromech. Microeng. 2009, 19, 054009. [CrossRef]

6. Belure, A.R.; Biswas, A.K.; Raghunathan, D.; Rishipal Bhartiya, S.; Singh Rashmi Rai, S.K.; Pawade, R.S.; Kamath, M.P.; Benerji, N.S. Development of super-smooth flat silicon mirror substrates using bowl-feed chemical-mechanical polishing. Mater. Today Proc. 2020, 26, 2260-2264. [CrossRef]

7. Li, J.; Liu, Y.; Dai, Y.; Yue, D.; Lu, X.; Luo, J. Achievement of a near-perfect smooth silicon surface. Sci. China Technol. Sci. 2013, 056, 2847-2853. [CrossRef]

8. Dong, Z.; Ou, L.; Kang, R.; Hu, H.; Zhang, B.; Guo, D.; Shi, K. Photoelectrochemical mechanical polishing method for n-type gallium nitride. Cirp Ann. Manuf. Technol. 2019, 68, 205-208. [CrossRef]

9. Lei, H.; Tong, K.; Wang, Z. Preparation of Ce-doped colloidal $\mathrm{SiO}_{2}$ composite abrasives and their chemical mechanical polishing behavior on sapphire substrates. Mater. Chem. Phys. 2016, 172, 26-31. [CrossRef]

10. Chen, Y.; Chen, A.; Qin, J. Polystyrene core-silica shell composite particles: Effect of mesoporous shell structures on oxide CMP and mechanical stability. Rsc. Adv. 2017, 7, 6548-6558. [CrossRef]

11. Nagase, T.; Kato, H.; Pahlovy, S.A.; Miyamoto, I.; Nakamura, Y. Ion beam sharpening of diamond tools having small apex angle without facet and ripple formations. J. Vac. Sci. Technol. Bmicroelectron. Nanometer Struct. Process. Meas. Phenom. Off. J. Am. Vac. Soc. 2009, 27, 2686-2690. [CrossRef]

12. Khatri, N.; Manoj, J.X.; Mishra, V.; Garg, H.; Karar, V. Experimental and simulation study of nanometric surface roughness generated during Magnetorheological finishing of Silicon. Mater. Today Proc. 2018, 5, 6391-6400. [CrossRef]

13. Wang, Y.; Zhang, Y.; Feng, Z. Analyzing and improving surface texture by dual-rotation magnetorheological finishing. Appl. Surf. Ence 2016, 360, 224-233. [CrossRef]

14. Anbarasu, K.G.; Vijayaraghavan, L.; Arunachalam, N. Experimental study on surface generation in optical glass with fluid jet polishing process. Int. J. Abras. Technol. 2018, 8, 245-260. [CrossRef]

15. Tangwarodomnukun, V.; Wang, J.; Huang, C.Z.; Zhu, H.T. Heating and material removal process in hybrid laser-waterjet ablation of silicon substrates. Int. J. Mach. Tools Manuf. 2014, 79, 1-16. [CrossRef]

16. Zhu, H.; Wang, J.; Yao, P.; Huang, C. Heat transfer and material ablation in hybrid laser-waterjet micro grooving of single crystalline germanium. Int. J. Mach. Tools Manuf. 2017, 116, 25-39. [CrossRef]

17. Takahiro, H.; Yoshinori, T.; Hidekazu, M. Machining Property in Smoothing of Steeply Curved Surfaces by Elastic Emission Machining. Procedia. Cirp. 2014, 13, 198-202.

18. Segall, M.D.; Lindan Philip, J.D.; Probert, M.J.; Pickard, C.J.; Hasnip, P.J.; Clark, S.J.; Payne, M.C. First-principles simulation: Ideas, illustrations and the CASTEP code. J. Phys. Condens. Matter 2002, 14, 2717-2744. [CrossRef]

19. Clark, S.J.; Segall, M.D.; Pickard, C.J.; Hasnip, P.J.; Probert, M.J.; Refson, K.; Payne, M.C. First principles methods using CASTEP. Z. Für Krist. Cryst. Mater. 2005, 220, 567-570. [CrossRef] 
20. John, P.; Perdew, J.A.; Chevary, S.H.; Vosko, K.A.; Jackson, M.R.; Singh, D.J.; Fiolhais, F.C. Singh, and Carlos Fiolhais. Atoms, Molecules, Solids, and Surfaces: Applications of the Generalized Gradient Approximation for Exchange and Correlation. Phys. Rev. B Condens. Matter. 1992, 46, 6671-6687.

21. Perdew, J.P.; Burke, K.; Ernzerhof, M. Generalized gradient approximation made simple. Phys. Rev. Lett. 1996, 77, 3865-3868. [CrossRef] [PubMed]

22. Augugliaro, V.; Yurdakal, S.; Loddo, V.; Palmisano, G.; Palmisano, L. Determination of Photoadsorption Capacity of Polychrystalline $\mathrm{TiO}_{2}$ Catalyst in Irradiated Slurry. Adv. Chem. Eng. 2009, 36, 1-35.

23. Tang, J.; Zou, Z.; Katagiri, M.; Kako, T.; Ye, J. Photocatalytic degradation of MB on MIn2O4 (M = alkali earth metal) under visible light: Effects of crystal and electronic structure on the photocatalytic activity. Catal. Today 2004, 93, 885-889. [CrossRef]

24. Xu, X.; Luo, J.; Guo, D. Nanoparticle-wall collision in a laminar cylindrical liquid jet. J. Colloid Interface Sci. 2011, 359, 334-338. [CrossRef]

25. Martin, L.; Martinez, H.; Ulldemolins, M. Evolution of the Si electrode/electrolyte interface in lithium batteries characterized by XPS and AFM techniques: The influence of vinylene carbonate additive. Solid State Ion. 2012, 215, 36-44. [CrossRef]

26. Pabianek, K.; Krukowski, P.; KPolański Ciepielewski, P.; Busiakiewicz, A. Interactions of Ti and its oxides with selected surfaces: Si (100), HOPG (0001) and graphene/4H-SiC (0001). Surf. Coat. Technol. 2020, 397, 126033. [CrossRef]

27. Chinh, V.D.; Broggi, A.; Palma, L.D.; Scarsella, M.; Speranza, G.; Vilardi, G.; Thang, P.N. XPS Spectra Analysis of Ti ${ }^{2+}$, Ti ${ }^{3+}$ Ions and Dye Photodegradation Evaluation of Titania-Silica Mixed Oxide Nanoparticles. J. Electron. Mater. 2018, 47, $2215-2224$. [CrossRef]

28. Zhang, H.; Luo, X.; Xu, J.; Xiang, B.; Yu, D. Synthesis of $\mathrm{TiO}_{2} / \mathrm{SiO}_{2}$ core/shell nano cable arrays. J. Phys. Chem. B 2004, 108, 14866-14869. [CrossRef]

29. Gao, X.; Wachs, I.E. Titania-silica as catalysts: Molecular structural characteristics and physico-chemical properties. Catal. Today 1999, 51, 233-254. [CrossRef] 